\title{
METABOLIC CHARACTERIZATION OF OVERWEIGHT AND OBESE ADULTS
}

\author{
Katie Rose Hirsch
}

A thesis submitted to the faculty at the University of North Carolina at Chapel Hill in partial fulfillment of the requirements for the degree of Master of Arts in the Department of Exercise and Sport Science (Exercise Physiology).

Chapel Hill

2016

Approved by:

Abbie E. Smith-Ryan

Eric D. Ryan

Kristin S. Ondrak 
(C) 2016

Katie Rose Hirsch

ALL RIGHTS RESERVED 


\begin{abstract}
Katie Rose Hirsch: Metabolic characterization of overweight and obese adults (Under the direction of Abbie E. Smith-Ryan)
\end{abstract}

Obesity is associated with diseases such as metabolic syndrome, but not all obese individuals have traditional markers of dysfunction like insulin resistance and dyslipidemia. To characterize metabolic health in 49 overweight and obese adults, body composition (fat mass [FM], lean mass [LM], percent body fat [\%fat]), was calculated using a 4-compartment model; visceral adipose tissue (VAT) was quantified using B-mode ultrasound. Resting metabolic rate (RMR), respiratory exchange ratio (at rest and during exercise), fasting lipids, insulin, and leptin were also analyzed. Fat mass, \%fat, and VAT correlated with insulin and leptin (r=0.369-0.829; $\mathrm{p}<0.05)$; FM was not correlated with lipids $(\mathrm{p}>0.05)$. Higher RMR was associated with LM $(\mathrm{r}=0.900, \mathrm{p}<0.001)$. When evaluating body composition and metabolism in addition to traditional metabolic syndrome criteria, individuals with disease risk increased from $29 \%$ to 80\%. Lean mass, VAT, RMR, and hormones may be indicators of metabolic dysfunction in the absence of traditional risk factors. 


\section{ACKNOWLEDGMENTS}

This project would not have been a success without the help and support of many. I would like to thank my committee members, Dr. Eric Ryan and Dr. Kristin Ondrak for their time and advice for improving this project throughout various stages. I would like to thank our lab team, Eric Trexler, Meredith Mock, and Malia Blue, for all the early mornings of data collection, trips to the Biobehavioral Lab, coordination of subjects, and all the laughs and smiles along the way. This project truly took a group effort and I would not have been able to do it without them. Most importantly, I would like to thank my advisor, Dr. Abbie Smith-Ryan, for her unfailing patience, ever appreciated advice, and continual guidance throughout every stage of this project and beyond. 


\section{TABLE OF CONTENTS}

LIST OF TABLES ..........................................................................................................

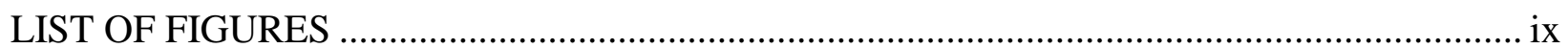

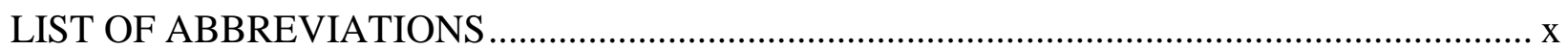

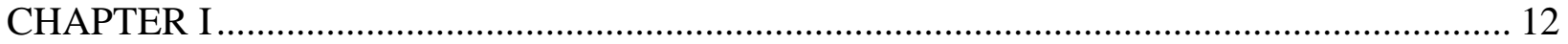

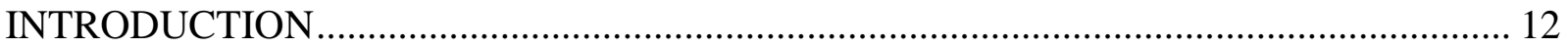

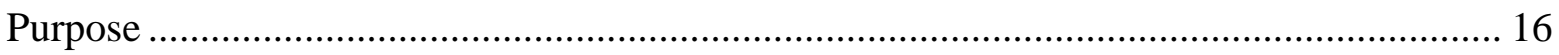

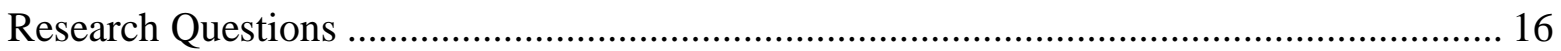

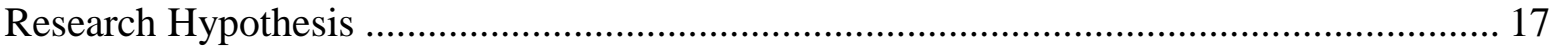

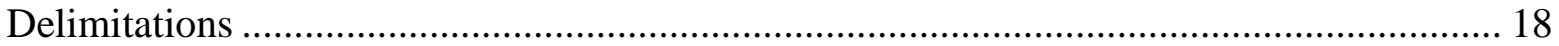

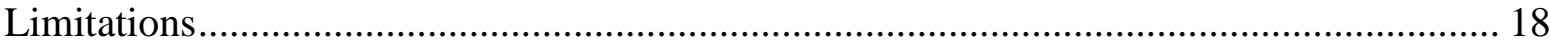

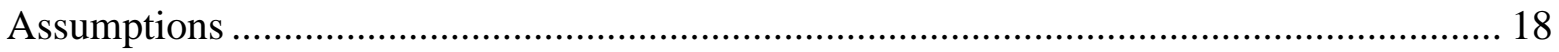

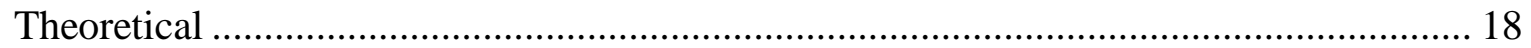

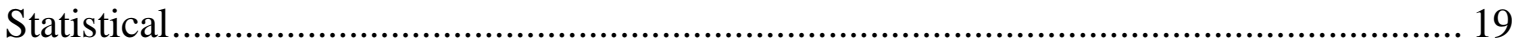

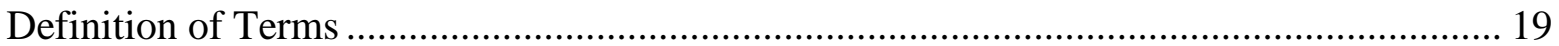

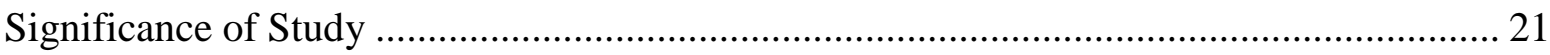

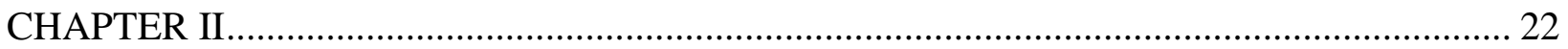




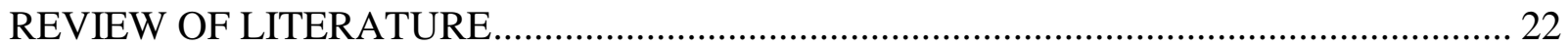

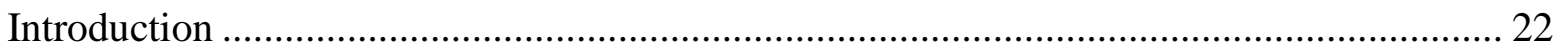

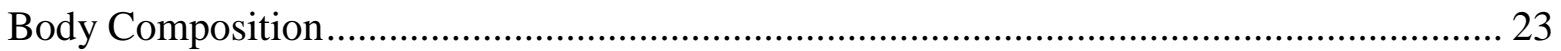

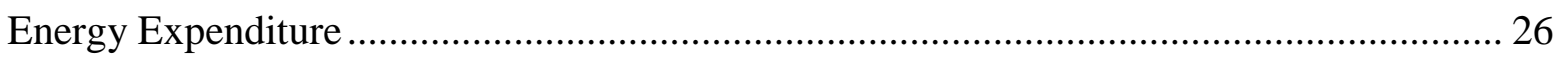

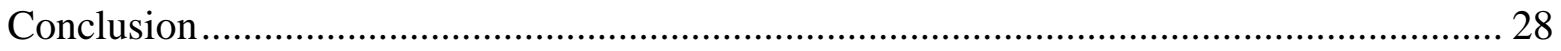

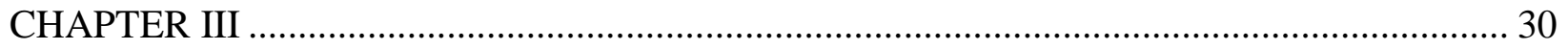

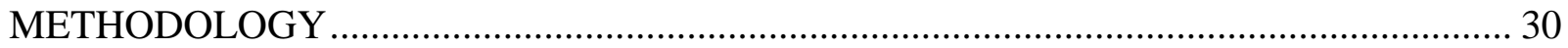

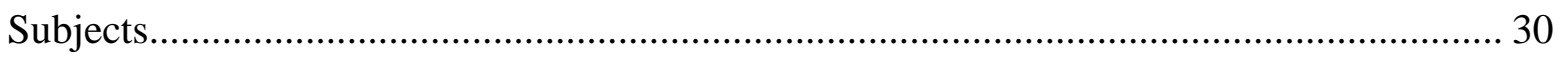

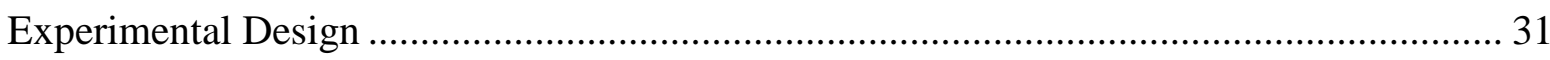

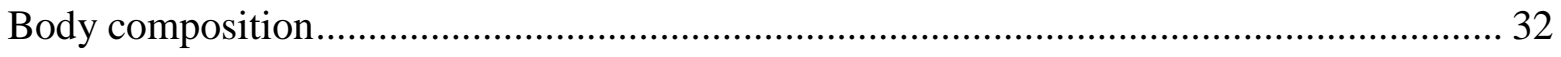

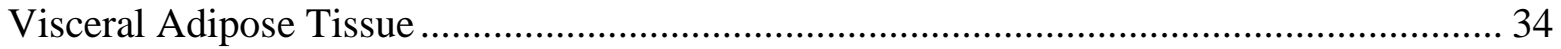

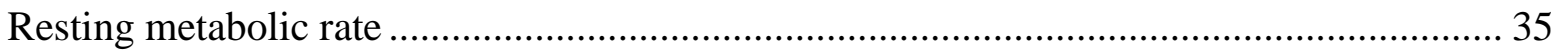

Blood Lipid and Hormone Analysis ................................................................... 35

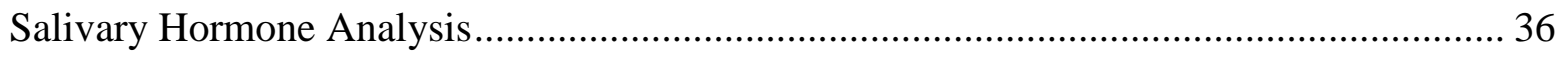

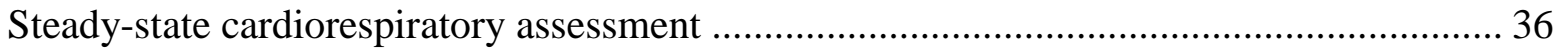

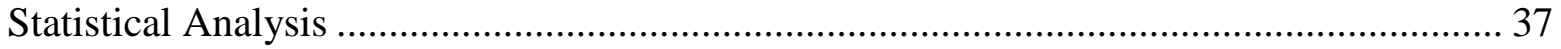

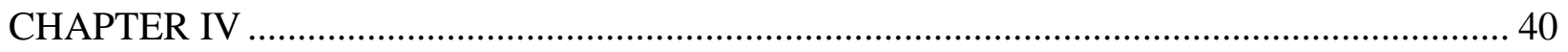

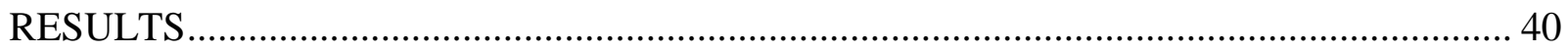

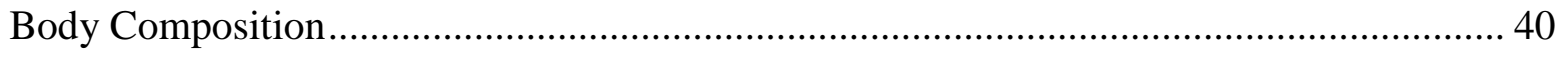

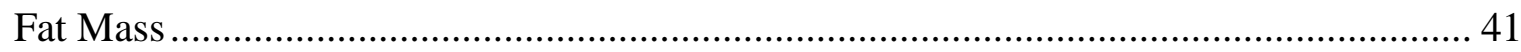




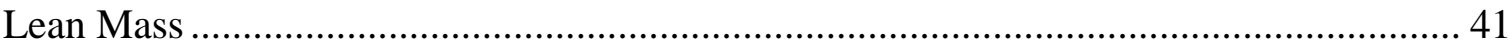

Percent Body Fat ........................................................................................ 42

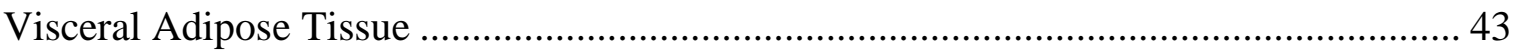

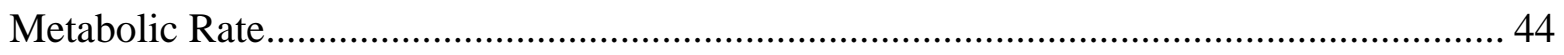

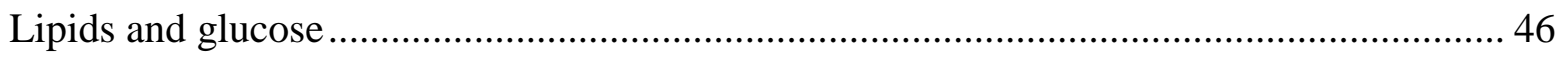

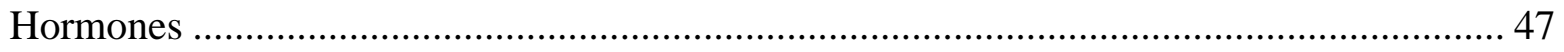

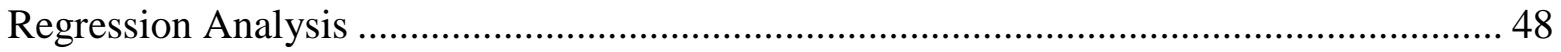

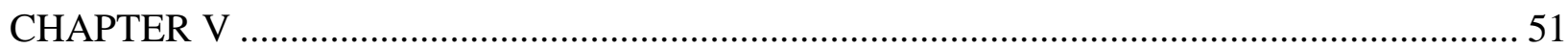

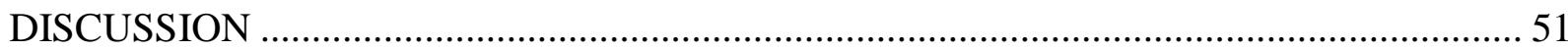

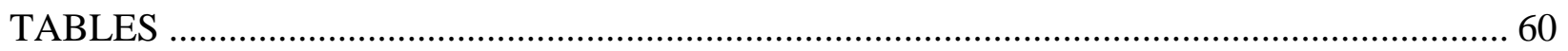

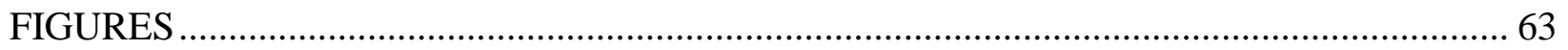

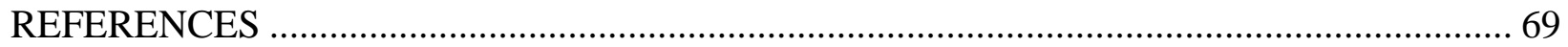




\section{LIST OF TABLES}

Table 1: Subject Characteristics ...............................................6 60

Table 2: Risk stratification and frequencies based on BMI, \%fat, and metabolic syndrome risk

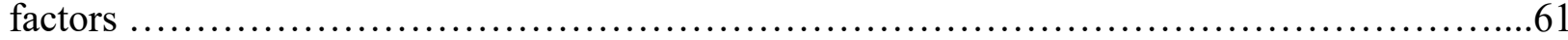

Table 3: Stratification and frequencies based on metabolic and hormonal factors .............62 


\section{LIST OF FIGURES}

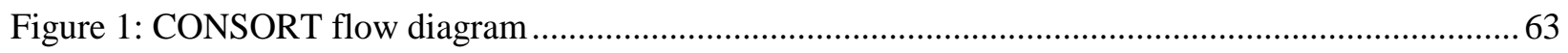

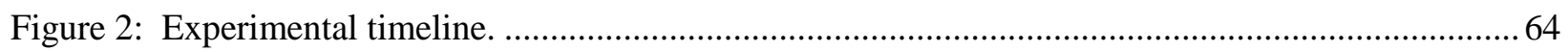

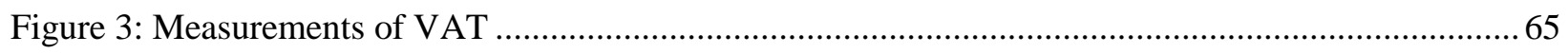

Figure 4: Resting metabolic rate ventilated canopy with indirect calorimetry. .................................... 66

Figure 5: Five females with LMI $>97^{\text {th }}$ percentile compared with the female group average ....................67

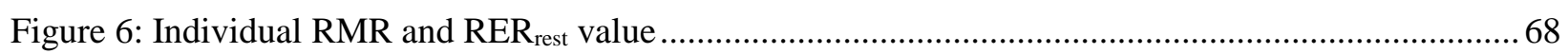




\section{LIST OF ABBREVIATIONS}

BIS Bioelectrical impedance spectroscopy

BMC Bone mineral content

BMI Body mass index

BV Body volume

BM Body mass

CT Computed topomyography

CVD Cardiovascular disease

DEXA Dual-energy x-ray absorptiometry

FM Fat mass

GLUC Blood glucose

HDL High density lipoproteins

HR Heart rate

$\mathrm{HR}_{\max } \quad$ Maximum heart rate

$\mathrm{HR}_{\text {rest }} \quad$ Resting heart rate

HRR Heart rate reserve

ICC Intraclass correlation coefficient

LDL Low density lipoproteins

LM Lean mass

LMI Lean mass index

MD Minimum difference

Mo Total body bone mineral density 
RER Respiratory exchange ratio

RER $_{\text {rest }} \quad$ Respiratory exchange ratio at rest

RER $_{\text {bike }} \quad$ Respiratory exchange ratio during the steady-state cardiorespiratory assessment

RMR Resting metabolic rate

SEM Standard error of measure

TBW Total body water

TC Total cholesterol

TRG Triglycerides

US B-mode ultrasound

VAT Visceral adipose tissue

$\mathrm{VAT}_{D E X A} \quad$ Visceral adipose tissue measured via dual-energy $\mathrm{x}$-ray absorptiometry

VAT $_{U S} \quad$ Visceral adipose tissue measured via B-mode ultrasound

4C Four-compartment model

$\triangle \mathrm{RER} \quad$ Change in respiratory exchange ratio; difference between $\mathrm{RER}_{\text {bike }}$ and $\mathrm{RER}_{\mathrm{rest}}$

\%fat Percent body fat 


\section{CHAPTER I}

\section{INTRODUCTION}

Metabolic syndrome is a chronic disease characterized by the presence of multiple risk factors that indicate metabolic dysfunction [1]. Many of these risk factors, such as insulin resistance and dyslipidemia, are also associated with an increased risk for the development of cardiovascular disease (CVD) and type 2 diabetes [1,2]. Currently, over two-thirds of adults in the United States are considered overweight or obese [3]. Of these individuals, an estimated $50 \%$ of overweight and about $70 \%$ of obese adults have at least two metabolic risk factors [4] placing a majority of the population at an increased risk for chronic diseases $[4,5]$. The associations between body fat and disease risk has resulted in decades of research with a primary focus on the reduction of body fat. While short-term success has been achieved, mainly through diet and exercise interventions, long-term maintenance is not as successful. About one third of adults who lose weight will have regained all of their weight after one year [6], with most regaining after five years [7]. The inability to maintain weight loss may suggest that other factors beyond fat mass (FM) are influencing metabolic health. Further, while metabolic syndrome is strongly associated with obesity [8], there are a number of obese individuals who are considered metabolically healthy exhibiting just one cardiometabolic risk factor [9]. Despite having normal blood lipid profiles (normal high-density lipoproteins; low plasma triglycerides) and being insulin sensitive $[10,11]$, the presence of excess body fat may be a sign of underlying metabolic dysfunction that could develop into metabolic syndrome. Factors such as visceral 
adipose tissue (VAT), lean mass (LM), resting metabolic rate (RMR), fuel utilization at rest and during exercise, and hormonal profiles, may give a more complete picture of metabolic health in overweight and obese adults, improving approaches to early identification of metabolic dysfunction.

Regional distribution of body fat, or where an individual stores their body fat, may be more highly associated with an increased risk of metabolic dysfunction, than the overall presence of excess body fat $[10,12]$. Previous studies have shown that high VAT, fat located within the abdominal cavity around the organs, is more significantly related to insulin resistance as opposed to subcutaneous adipose tissue $[12,13]$. In a study by Brochu et al. (2001), insulin resistance was more prevalent in obese women with greater VAT when matched for total body and abdominal subcutaneous fat. Further, in the absence of excess body fat, normal weight individuals with increased VAT, also demonstrate a greater prevalence of insulin resistance [12]. The strong association between VAT and insulin resistance has resulted in VAT being regarded as more harmful to metabolic health. However subcutaneous fat may still have a significant impact on metabolic regulation. Subcutaneous adipose tissue not only serves as a storage location for excess energy, but it also serves as an important endocrine organ [14]. Previously shown to be related to the production and balance of metabolic hormones, excess subcutaneous fat may lead to hormonal imbalances that promote metabolic dysfunction [15]. Leptin specifically, is more strongly associated with subcutaneous and overall body fat than VAT, [12, $16,17]$. Leptin is a hormone secreted by adipose tissue as a signal of chronic energy stores (fat mass) that serves as a regulator of energy balance [18]. Since obese individuals have excess body fat, high concentrations of leptin should decrease energy intake and increase energy expenditure, promoting a return to normal weight. However, obese individuals with high leptin 
levels often have no associated changes in FM and energy expenditure, potentially symbolizing leptin resistance [18]. Despite its potential physiological function, the role of leptin in energy expenditure is not completely understood. There is some recent speculation that there may be an inhibitory relationship between insulin and leptin, with high insulin levels blocking the leptin signal and promoting energy storage [19]. It has also been theorized that high leptin levels may increase RMR, but this relationship has not yet been observed in humans [20, 21]. Other hormones that have associations with fat distribution are estrogen and cortisol. Estrogen has been shown to influence fat distribution by increasing gynoid and subcutaneous fat accumulation $[12,15,22]$. Low estrogen levels in obese women are associated with increases in VAT, while high levels estrogen in obese men may have similar consequences [23-25]. In contrast, cortisol, commonly associated with an elevated stress response, has been shown to be associated with greater body fat and VAT, which over time could lead to changes in substrate metabolism and insulin resistance [26-28]. Evaluation of hormonal profiles in relation to fat distribution may be an important indicator of metabolic health in the absence of traditional markers. Fat distribution is typically evaluated in clinical settings using waist circumference measurements, which do not differentiate between visceral and subcutaneous distribution. Recently validated techniques such as ultrasonography (US) may be a feasible option for clinical evaluation of abdominal fat distribution, but further evaluation of its clinical utility is needed.

In contrast to the negative relationship between total and regional fat distribution and metabolic health, LM is typically beneficial to metabolic health. As the major location for glucose storage and metabolism, LM is commonly overlooked in the context of obesity and metabolic disease. Lean mass has a significant impact on energy expenditure, accounting for up to $63 \%$ of the inter-individual variability in RMR [29]. Losses in LM are associated with 
decreases in RMR, insulin resistance, and poor functionality [30], all of which are associated with weight gain. Lean mass may also be important in fuel utilization and maintaining metabolic flexibility. At rest, a healthy individual typically derives a greater portion of their energy from fat oxidation. During exercise or after eating a meal with a reasonable amount of carbohydrates, carbohydrate oxidation increases to match the greater energy demand. Impaired fat oxidation at rest and chronic reliance on carbohydrate oxidation is a sign of metabolic dysfunction and is considered to be a risk factor for weight gain $[28,31]$. The metabolic consequences of low LM, and conversely the potential benefits of greater LM, supports the importance of evaluating LM in obese populations.

In order to gain a better understanding of metabolic health in overweight and obese adults, better characterization of this population is necessary. Insulin resistance and dyslipidemia are an indication of metabolic dysfunction, but in their absence, other factors may be a sign of a developing dysfunction. Better characterization of fat distribution and its relation to adipose related hormones, like insulin, leptin, estrogen, and cortisol may give further insights into the metabolic consequences of hormonal imbalance. Differences in fat distribution, especially between males and females, may have different effects on hormonal balance and metabolic regulation, which could serve as a risk factor for development of metabolic syndrome. Further, consideration of LM, RMR, and fuel utilization determined from respiratory exchange ratio $(\mathrm{RER})$ at rest $\left(\mathrm{RER}_{\text {rest }}\right)$ and during steady-state exercise $\left(\mathrm{RER}_{\text {bike }}\right)$ in relation to FM, percent body fat (\%fat) and hormonal profiles may influence future approaches to obesity interventions. 


\section{$\underline{\text { Purpose }}$}

1. The primary purpose of this study was to characterize metabolic health in overweight and obese adults by evaluating body composition (FM, LM, \% fat, VAT), RMR, RER rest, RER $_{\text {bike, }}$ glucose, lipids, and hormones (insulin, leptin, estrogen, cortisol).

a. A component of this purpose assessed the relationships between these variables, as well as differences between overweight and obese.

2. A secondary purpose of this study was to evaluate sex differences between body composition (FM, LM, \%fat, VAT), RMR, RER ${ }_{\text {rest }}$, RER $_{\text {bike, glucose, lipids, and }}$ hormones (insulin, leptin, estrogen, cortisol).

a. A component of this purpose assessed sex differences, while also accounting for dietary intake and LM.

3. A tertiary purpose of this study was to assess how well variances in non-standard factors of metabolic health (FM, LM, \%fat, VAT, RMR, RER rest $_{\text {, RER }}$ bike, $\Delta$ RER), were explained by standard clinical measures of metabolic health (glucose, lipids, insulin, leptin, estrogen, cortisol).

a. A component of this purpose assessed how well variances in non-standard factors of metabolic health were explained by standard clinical measures of metabolic health, including VAT as a potentially feasible clinical factor.

\section{$\underline{\text { Research Questions }}$}

1. Is there a relationship between total and regional body composition, RMR, RER rest$_{\text {, }}$ RER $_{\text {bike, }}$ glucose, lipids, and hormones in overweight and obese adults?

2. Is there a relationship between leptin, RMR and RER rest $_{\text {, }}$ RER $_{\text {bike? }}$ ? 
3. Are there differences in total and regional body composition, RMR, RER rest $_{\text {, }}$ RER $_{\text {bike, }}$, glucose, lipids, and hormones between overweight and obese adults?

4. Are there differences in RMR, RER rest,$R R_{\text {bike, }}$, glucose, lipids, and hormones between men and women, when accounting for dietary intake and body composition?

5. Will variances in total and regional body composition, $R M R, R_{\text {rest }}, \mathrm{RER}_{\text {bike, }}$ and $\triangle$ RER be explained by blood and hormonal markers of metabolic health?

6. Are there differences in relationships between VAT and markers of metabolic health when measured via B-mode US or dual-energy x-ray absorptiometry (DEXA)?

\section{$\underline{\text { Research Hypothesis }}$}

1. Fat mass, \%fat, and VAT would be positively correlated and LM would be negatively correlated with compromised lipid levels (plasma triglycerides, HDL) and hormonal profiles (insulin, leptin, estrogen, cortisol).

2. Fat mass, \%fat, and VAT would be negatively correlated and LM would be positively correlated with RMR; FM, \%fat, and VAT would be positively correlated and LM would be negatively correlated with RER.

a. There would be a significant relationship between leptin levels, RMR, RER rest, $_{\text {, }}$ and RER bike.

3. There would be differences in RMR, $R R_{\text {rest }}, R R_{\text {bike, }}$, glucose, lipids, between men and women, after accounting for dietary intake and body composition. There would be no differences between men and women in RMR when controlled for differences in body mass and LM, while women will have a lower RER than men. Men would have higher fasting insulin concentrations, while women would have higher leptin and estrogen levels. There would be no sex differences in cortisol levels. 


\section{$\underline{\text { Delimitations }}$}

1. Subjects were between the ages of 18-55 years.

2. Healthy men and pre-menopausal women were recruited.

3. Subjects had a BMI of $25-52 \mathrm{~kg} \cdot \mathrm{m}^{-2}$ and/or body fat percentage between $25-53 \%$.

4. Subject were not taking any dietary supplements or using a meal replacement.

5. Subjects were not consuming a low-carbohydrate or ketogenic diet.

6. Body composition was measured by 4-compartment model.

7. Visceral adipose tissue was measured by B-mode US and DEXA.

8. Insulin, leptin, and lipid levels were measured from a blood draw.

9. Estradiol and cortisol concentrations were measured from a saliva sample.

10. Indirect calorimetry was used to measure RMR, RER $\mathrm{rest}_{\text {and }}$ RER $\mathrm{R}_{\text {bike. }}$

\section{$\underline{\text { Limitations }}$}

1. Visceral adipose tissue was measured using US, rather than computed tomography (CT) scan which is considered the gold standard.

2. Indirect calorimetry was used to measure $R M R, R^{2} R_{\text {rest }}$ and $R R_{\text {bike }}$, rather than direct calorimetry which is considered the gold standard.

3. A cross-sectional design will characterize overweight and obese individuals at a single point in time, but does not allow for evaluation of potential risk factors over time.

\section{$\underline{\text { Assumptions }}$}

\section{Theoretical}

1. Subjects accurately reported health and exercise history information.

2. Subjects provided accurate dietary intake information on nutrition logs.

3. Subjects followed pre-testing exercise and dietary guidelines. 


\section{Statistical}

1. The population from which the sample was taken was normally distributed.

2. The sample variability was equal.

\section{Definition of Terms}

Overweight - having a BMI of $25-29.9 \mathrm{~kg} \cdot \mathrm{m}^{-2}$

Obese - having a BMI of $30-45 \mathrm{~kg} \cdot \mathrm{m}^{-2}$

Fat mass (FM) - all extractable lipids that can be extracted from adipose and other tissues [32].

Lean mass $(L M)$ - all residual lipid-free chemicals and tissues including water, muscle, connective tissue, organs, and bone [32].

Percent body fat (\%fat) - fat mass expressed as a percentage of total body weight

Total body volume [33] - estimate of body size and density using air displacement [32].

Total body water $(T B W)$ - a measure of the intracellular and extracellular fluid compartments of the body estimated using bioelectrical impedance spectroscopy [32].

Total body bone mineral density $(\mathrm{Mo})$ - a measure of the bone mineral content of the body estimated using dual-energy $\mathrm{x}$-ray absorptiometry [32].

Body Mass (BM) - body weight measured in kilograms [32].

Visceral adipose tissue (VAT) - intra-abdominal adipose tissue; quantified as a measurement of adipose tissue that exists between the interior border of the rectus abdominis and the posterior wall of the aorta [34-36].

Estradiol - a female sex hormone; measured using a salivary estradiol ELISA kit $(\mathrm{pg} / \mathrm{mL})$

Cortisol-glucocorticoid involved with maintaining blood glucose; free cortisol concentrations measured using a salivary cortisol ELISA kit $(\mu \mathrm{g} / \mathrm{dL})$.

Blood glucose - measure of glucose concentrations in the blood $(\mathrm{mg} / \mathrm{dL})$ 
Total cholesterol - measure of all cholesterol in the blood $(\mathrm{mg} / \mathrm{dL})$

Triglycerides - measure of fats in the blood $(\mathrm{mg} / \mathrm{dL})$

$H D L$ - high density lipoproteins in the blood $(\mathrm{mg} / \mathrm{dL})$

$L D L$ - low density lipoproteins in the blood $(\mathrm{mg} / \mathrm{dL})$

$L M I$ - Lean mass index $\left(\mathrm{LM}[\mathrm{kg}] / \mathrm{m}^{2}\right)$

Insulin - hormone promoting glucose uptake from the blood $(\mathrm{uIU} / \mathrm{mL})$

Leptin - adipose hormone signaling energy stores $(\mathrm{ng} / \mathrm{mL})$.

Maximum Heart Rate $\left(H R_{\max }\right)$ - estimate of the greatest number of beats per minute that can be achieved by the heart (220-age)

Heart Rate Reserve $(H R R)$ - difference between maximum heart rate and resting heart rate used to prescribe exercise intensities; Karvonen formula $\mathrm{HRR}=\left[\mathrm{HR}_{\max }-\mathrm{HR}_{\mathrm{rest}}\right] \mathrm{x}$ \%intensity $+\mathrm{HR}_{\text {rest }}$

Resting metabolic rate $(R M R)$ - energy expended while at rest in a supine position, but still awake, as measured using indirect calorimetry (kcal/day) [37].

Respiratory exchange ratio (RER) - a measure of fuel utilization that uses a ratio of carbon dioxide expired to volume of oxygen consumed to estimate the contribution of fat and carbohydrate to energy expenditure at rest and during submaximal exercise.

Respiratory exchange ratio at rest $\left(R E R_{\text {rest }}\right)$ - Respiratory exchange ratio measured during a resting state.

Respiratory exchange ratio during steady-state $\left(R E R_{b i k e}\right)$ - Respiratory exchange ratio during a steady-state cycle ergometer bout.

Change in respiratory exchange ratio during steady-state $(\triangle R E R)$ - Change in respiratory exchange ratio; difference between $\mathrm{RER}_{\text {bike }}$ and $\mathrm{RER}_{\text {rest }}$ 


\section{$\underline{\text { Significance of Study }}$}

This study evaluated the relationships between body composition, RMR, RER, glucose, lipids, and hormones in order to better characterize overweight and obese individuals. In order to gain a better understanding of factors that place these individuals at an increased risk of metabolic syndrome, a more comprehensive analysis of body composition, beyond the use of BMI, should be used to categorize and assess overweight and obese individuals. This study used a 4-compartment (4C) model and US in order to assess FM, LM, \%fat, and VAT. A 4C model incorporates measures from multiple methods of assessing body composition, for a more accurate estimation, while US may be a feasible option for a more direct measures of VAT. Body composition, RMR, RER, and hormones have previously been assessed separately in obese populations, but have not been assessed together, which may provide insight into relationships between factors. This study also attempted to gain a better understanding of the relationships between leptin, body composition, RMR, and RER. Finally, evaluating RMR and RER in relation to body composition, glucose, lipids, and hormones, may provide information that can be used to promote long term metabolic health. 


\section{CHAPTER II}

\section{REVIEW OF LITERATURE}

\section{$\underline{\text { Introduction }}$}

There is a well-established association between obesity and an increased risk of chronic diseases, such as cardiovascular disease, type II diabetes, and metabolic syndrome $[4,5]$. Metabolic syndrome is a disease defined by the presence of three or more risk factors related to an increased risk of cardiovascular disease, which include: abdominal obesity (waist circumference: men>102 cm; women $>88 \mathrm{~cm})$, elevated triglycerides $(\geq 150 \mathrm{mg} / \mathrm{dl})$, low HDL cholesterol (men<40 mg/dl; women $<50 \mathrm{mg} / \mathrm{dl}$ ), high blood pressure $(\geq 130 / 85 \mathrm{~mm} / \mathrm{Hg})$, and elevated glucose $(\geq 110 \mathrm{mg} / \mathrm{dl})$ [1]. Obese individuals $\left(\mathrm{BMI} \geq 30 \mathrm{~kg} / \mathrm{m}^{2}\right)$ have been shown to have the highest prevalence of metabolic syndrome $[8,13]$, likely related to complications associated with high amounts of adiposity. Increased FM and a higher \%fat is associated with decreased insulin sensitivity $[9,12,38]$, and poor lipid profiles, primarily high plasma triglycerides and low HDL [13]. Despite short term success at weight loss, $33.5 \%$ of individuals will regain weight after only one year [6]. The prevalence of obesity and the inability to maintain long term weight loss may be an indication of metabolic dysfunction beyond the presence of body fat. Comprehensive characterization of the body composition, hormonal profile, and metabolic rate may provide greater insight into metabolic health of overweight and obese individuals. 


\section{$\underline{\text { Body Composition }}$}

Many studies use insulin sensitivity as the primary defining factor of metabolic health due to the association of insulin resistance with the development of type 2 diabetes, hypertension, and cardiovascular disease [5, 39]. Excess adiposity, especially in the abdominal region, has been shown to be associated with insulin resistance and poor lipid profiles. In a study by Brochu et al (2001), obese postmenopausal women who were insulin resistant had significantly more VAT than women who were insulin sensitive when matched for whole body FM and abdominal subcutaneous fat. In the same study, VAT was also found to be an independent predictor of both insulin sensitivity and fasting plasma triglyceride concentrations. Other studies have reported similar findings with higher amounts of VAT being associated with insulin resistance and poor lipid profiles [11]. In contrast, other studies have demonstrated associations with subcutaneous fat [40]. Discrepancies may be the result of population and sex differences, as well as the method used for evaluation of body composition. Computed topomyography (CT) is considered the criterion method for assessing VAT [41]; however, CT scans are expensive, time consuming, and are not always a feasible option at the clinical level when assessing large populations. Waist circumference and waist-to-hip ratio are often used to assess abdominal obesity, due to ease and portability, yet provide a more global assessment of fat distribution. Recently, US has been recognized as a valid measure of VAT compared to CT [42, 43]. US may provide a more affordable and feasible way to assess VAT. Due to the portability, US may allow for a more accurate assessment of VAT in a variety of settings. As a result of potential impacts and feasibility, more research utilizing US for determining associations between fat distribution and other components of metabolic health may be valuable. 
There is a growing body of research focusing on the hormonal profile of obesity and metabolic dysfunction. Hormones such as adiponectin, resistin, leptin, and ghrelin are important hormones involved in the regulation of appetite and energy balance [18, 44]. Leptin in particular is produced by adipose tissue as an indication of long term energy stores (body fat). While details of the leptin mechanism are not completely understood, high levels of circulating leptin activates receptors on the hypothalamus. This triggers an endocrine response that promotes metabolic rate and initiates satiety. In contrast, low leptin levels signal a lack of energy or starvation, triggering an endocrine response that promotes energy storage $[18,44]$. Disruptions to this feedback loop, have been shown to result in increased FM and appetite in obese individuals, attributed to leptin deficiency or leptin resistance. While leptin levels are positively correlated with BMI and \%fat $[16,21,45,46]$, a wide range of concentrations have been reported for obese individuals [46, 47]. Many obese individuals with high leptin levels, still have normal to high food intake and leptin treatments for deficiency have had limited effects on weight loss, indicating leptin resistance [19]. While the mechanism for leptin resistance is currently unknown, potential influences of fat distribution and interactions with other hormones are potential factors. Despite the general positive association between leptin and \%fat, it is unclear whether leptin has stronger associations with VAT or subcutaneous fat $[16,46]$, though there is some suggestion of a greater association with subcutaneous fat $[12,16,17]$. Leptin and insulin have been shown to circulate in the bloodstream in proportion to FM [19]. Elevated insulin concentrations, as would be observed in insulin resistant type 2 diabetics or those with metabolic syndrome, may have inhibitory effects on leptin with competing signals to the hypothalamus [19]. Estrogen may also have interactions with leptin production as women are regularly reported as having higher leptin levels compared to men [12, 17, 21, 46]. Estrogen is 
also thought to influence fat distribution with estrogen concentrations showing greater associations with subcutaneous fat accumulation in women [12, 48]. Like estrogen, elevated cortisol levels may promote VAT accumulation which could lead to insulin resistance [26, 27]. Cortisol is a stress related hormone that helps maintain blood glucose levels. Stressors include diet, exercise, environmental stress, emotional stress, and sleep deprivation [26]. High cortisol levels have been observed in association with greater amounts of VAT [27], but it is still unclear if elevated cortisol promotes VAT accumulation or vice versa [49].

An additional component of body composition that is commonly overlooked in the context of obesity is LM. Lean mass is a major site for insulin binding and subsequent glucose uptake. Increased FM or intramuscular fat infiltration can interfere with glucose uptake, either by decreasing insulin sensitivity or by inhibiting glucose oxidation [50]. Over time, insulin resistance may develop, leading to the development of metabolic syndrome and type 2 diabetes [30]. Loss of LM itself decreases the location for insulin binding which can exacerbate diseases such as cardiac cechaxia, sarcopenia, osteoporosis, and type 2 diabetes [30]. Lean mass is also a major contributing factor to RMR, the largest component of energy expenditure [29]. Decreases in LM are associated with decreases in RMR, which can lead to energy imbalance and weight gain [29]. Further, a condition known as sarcopenic obesity is characterized by low LM and a poor strength-to-body size ratio [51]. Low LM and poor strength directly impact functionality, decreasing overall quality of life and the ability to perform activities of daily living [52]. Despite its important physiological role in insulin sensitivity, energy balance, and functionality, LM is often not quantified in overweight and obese populations. Most research is focused on the consequences of fat accumulation, but effectively losing FM has proven to be difficult, as observed in the continued prevalence of obesity. Lean mass is more metabolically active than 
FM making it more adaptable. Increasing LM may be a more effective approach to changing body composition that would also lead to improvements in other areas of metabolic health, such as hormonal profiles and energy expenditure. The characterization of whole body and regional LM in overweight and obese populations in relation to specific hormones is needed in order to better understand metabolic health in this population.

\section{Energy Expenditure}

In its most basic definition, obesity is the result of energy imbalance. When energy intake exceeds energy expenditure, weight gain typically ensues [53]. Energy expenditure has four components: RMR, thermic effect of food, non-exercise adaptive thermogenesis, and physical activity energy expenditure [54]. Alterations in body composition and hormonal profile may cause changes in RMR that could promote weight gain and resistance to weight loss.

Resting metabolic rate accounts for the largest caloric requirements of energy expenditure [55]. A lower RMR is often associated with weight gain [53] and is highly influenced by the presence of LM [29, 55]. Johnstone et al. (2005) reported that LM accounted for $63 \%$ of between-subject variance in RMR. Of the remaining 36\%, about $9 \%$ was explained by differences in FM, age, and analytic error, and 27\% was unexplained. Hormonal factors, such as leptin, may explain some of this variation. Chronically, circulating leptin concentrations drop significantly with changes in body fat in response to decreasing energy stores [20]. Acutely, leptin concentrations have also been shown to significantly decrease during times of caloric restriction, as might occur during a period of fasting or dieting [56]. As discussed earlier, low leptin levels are interpreted by the hypothalamus as a state of energy deprivation, which triggers a cascade of hormonal responses that promotes a physiological state of energy conservation [18, 44], such as a lower RMR. While leptin is referenced as having an impact on RMR, there is little 
support for this relationship. Leptin has been shown to influence RMR in mice [57], while most human studies to date show no relationship between circulating leptin levels and metabolic rate [29]. Estrogen may also have effects on metabolic rate. Resting metabolic rate has been shown to vary considerably with the menstrual cycle [58], an important factor to consider when characterizing metabolic health in premenopausal women.

Fuel utilization, or the contribution of fat and/or carbohydrate being used as the primary fuel source at rest and during exercise may also be an important factor in weight regulation. Respiratory exchange ratio is the ratio of carbon dioxide production to oxygen consumption used to estimate substrate oxidation by way of indirect calorimetry [59]. An RER of 0.7 indicates primarily fat oxidation, while an RER of 1.0 indicates primarily carbohydrate oxidation, with a combination of the two falling within that range [59]. Diet seems to have the strongest impact on RER [60], with carbohydrate reliance increasing with chronic overfeeding, regardless of fat and carbohydrate content [61]. Larson et al. (1995) found that formerly obese individuals had significantly higher 24-hour and resting RER than normal weight subjects, indicating a chronic reliance on carbohydrate as a fuel source [62]. Kelley et al. (1999) also found obese individuals to have high glucose uptake and oxidation at rest, with little to no changes observed after feeding. The lack of change in fuel utilization from rest may be an indication that obese individuals have impaired fat oxidation which may be associated with an increased risk of weight gain $[31,63]$. Further, women tend to derive more of their energy from fat, while men derived more energy from carbohydrates $[64,65]$, but metabolic inflexibility may blunt these differences [66]. Despite potential relationships between obesity and sex on fuel utilization, RER in obese individuals is still highly variable, ranging anywhere from 0.799 a.u. to 0.903 a.u. [31, 67]. To 
date, the relationship of total and regional body fat and RER in overweight and obese men and women has not been fully explored.

\section{Conclusion}

There is growing evidence that obesity is a multifaceted issue, with interconnected factors related to body composition, metabolic rate, fuel utilization, and hormonal balance. The complications and potential factors that should be considered when evaluating the metabolic health of an obese individual extends far beyond what can be determined from a BMI category. In order to critically assess the impact excess body fat and altered body composition has on other aspects of metabolic health, the most sophisticated measurement techniques must be utilized. Using a 4C model to assess body composition provides a more accurate measure of FM, LM, and \%fat over BMI, by accounting for additional compartments such as water and bone [68]. This level of precision provides a stronger basis from which to assess relationships of total body and regional fat distribution and LM with other aspects of metabolic health. Further, US and DEXA are both validated techniques for evaluating VAT, which has important implications for clinical evaluation of metabolic health risk factors. Specifically, US may be a feasible option for VAT quantification related to its portability and availability in many clinical settings, but the clinical utility requires further evaluation.

Associations between hormones such as insulin, leptin, estrogen, and cortisol, have not been clearly established in their relationship to obesity. Insulin resistance is associated with excessive total body fat, but not all obese individuals are insulin resistant. Leptin has been shown to be positively associated with \%fat, but with high between-subject variability. There is also growing evidence for relationships between fat distribution and hormonal balance, but further evaluation of this relationship, especially in the context of sex differences, is needed. 
Together, body composition and hormonal status may be associated with an altered state of energy balance and fuel utilization, promoting a state of weight gain and a resistance to weight loss. Comprehensive evaluation of relationships between total body fat, fat distribution, LM, metabolic hormones, RMR, and RER, may prove valuable when characterizing overweight and obese populations, in hopes of gaining a better understanding of metabolic health. 


\section{CHAPTER III}

\section{METHODOLOGY}

\section{$\underline{\text { Subjects }}$}

Approximately 114 individuals provided initial interest in study participation. After electronic correspondence, 64 individuals qualified to complete in-person inclusion/exclusion review. After the in-person enrollment visits, eight individuals were excluded from participation based on violation of inclusion/exclusion criteria, resulting in a cohort of 56 individuals enrolled in the study. An additional seven individuals withdrew from participation prior to testing for personal reasons. Therefore, forty-nine overweight and obese men $(n=23)$ and women $(n=26)$ between the ages of 18 and 55 years participated in this study (Mean \pm SD; Age $=35.0 \pm 8.9$ yrs; $\mathrm{BMI}=33.6 \pm 5.2 \mathrm{~kg} \cdot \mathrm{m}^{-2} ; \%$ fat $=40.0 \pm 7.3 ;$ Race: White=32; Black=13; Hispanic=2; Asian=2) Full subject characteristics stratified by sex can be found in Table 1. Full recruitment and enrollment can be found in Figure 1. All subjects were healthy, as reported on the health history questionnaire, having no history of medical or surgical events that may have significantly affected study outcome, including cardiovascular disease, diabetes, renal, hepatic, or musculoskeletal disorders. Women were categorized as pre-menopausal, determined as reporting consistent menstruation for three months prior. Subjects were considered overweight or obese, defined as having a BMI of $>25 \mathrm{~kg} \cdot \mathrm{m}^{-2}$ for women, $>27 \mathrm{~kg} \cdot \mathrm{m}^{-2}$ for men, and/or having a \%fat of $>25 \%$. All subjects were considered weight stable, not having lost or gained greater than ten pounds within the three months prior to the enrollment date. Subjects were not allowed 
to participate in the study if they report using a meal replacement or dietary supplements including whey protein, beta-alanine, creatine, carnosine, or taurine within eight weeks prior to enrollment. Subjects consuming a low-carbohydrate or ketogenic diet at the time of enrollment excluded from participation. Subjects were not allowed to participate in the study if they have participated in another clinical trial within four weeks prior to enrollment. Subjects agreed to maintain their usual activity lifestyle, abstain from smoking, caffeine, tobacco, and alcohol before testing days, provide written and dated informed consent, and were willing and able to comply with the testing protocol.

\section{Experimental Design}

In a cross sectional design, subjects reported to the Applied Physiology Laboratory in Fetzer Hall to complete three different testing sessions (Figure 2). Subjects were recruited from Chapel Hill, Raleigh, Durham, and the surrounding area by the use of flyers and word of mouth. Subjects who expressed interest in participating in the study were sent an electronic copy of the informed consent and a 4-day dietary intake log in which to record their dietary intake on two weekdays and two weekend days. The dietary log, which is a standardized log used to obtain dietary information, was completed prior to visit one to allow time for dietary analysis. During the first visit (enrollment), subjects provided written informed consent, completed a health history questionnaire, and completed anthropometric measures of height (cm; stadiometer: Perspective Enterprises, Portage, MI), weight (kg; digital scale: Health o meter: 2101KL, Bridgeview, IL), BMI, and age to ensure inclusion/exclusion criteria. A baseline dietary analysis and interpretation was done for each participant based on the 4-day dietary food log to account for any baseline food influences and provided subjects with basic dietary recommendations. Dietary recommendations were standardized for all participants and based off of the Harvard 
Healthy Eating Plate. Following consent and enrollment, a two-week run in period, followed by a 24-hour dietary log, separated visit one and visit two in order to allow dietary intake to normalize. To ensure normalization, the 24-hour dietary log recorded everything that was consumed during the 24 hours prior to visit two and was compared to intake reported from the 4day log. Visit two consisted of measures of body composition, RMR, RER rest, and blood and salivary samples. All tests were performed first thing in the morning. Subjects arrived at least eight hours fasted (consuming no food or beverage except for water) wearing light-weight clothing; all metal and heavy plastic that could interfere with body composition measurements were removed. Visit three consisted of a steady-state cardiorespiratory assessment. Subjects arrived at least four hours fasted to visit three. Visits two and three were separated by 24 hours ( \pm 72 hours). All devices were calibrated to manufacturer standards prior to testing to ensure valid results.

\section{Body composition}

Fat mass, LM, and \%fat were calculated using a 4C model described by Wang et al. (2002) (Equation 1), where BV is total body volume, TBW is total body water, Mo is total body bone mineral density, and BM is body mass measured in kilograms [68].

Equation 1: $\quad F M(\mathrm{~kg})=2.748(\mathrm{BV})-0.699(\mathrm{TBW})+1.129(\mathrm{Mo})-2.051(\mathrm{BM})$

$$
\begin{aligned}
& \% \text { fat }=(\mathrm{FM} / \mathrm{BM}) \times 100 \\
& \mathrm{LM}(\mathrm{kg})=\mathrm{BM}-\mathrm{FM}
\end{aligned}
$$

Test-retest reliability for the $4 \mathrm{C}$ from our lab in a similar population are as follows: fat mass intraclass correlation coefficient $($ ICC $)=0.994$, standard error of measure $(\mathrm{SEM})=0.830 \mathrm{~kg}$, and minimum difference $(\mathrm{MD})=2.30 \mathrm{~kg}$; \% fat $\mathrm{ICC}=0.988, \mathrm{SEM}=0.868 \%, \mathrm{MD}=2.40 \%$, and $\mathrm{LM}$ ICC $=0.996, S E M=0.842 \mathrm{~kg}, \mathrm{MD}=2.33 \mathrm{~kg}$. 
Air-displacement plethysmography (BodPod®, COSMED USA, Inc., Concord, CA, USA) was used to determine BV and BM. In a private room, the subjects were asked to wear tight fitting clothing, such as a bathing suit or spandex, and given a swimming cap to wear on their head. Identification code, age, sex, ethnicity, height $(\mathrm{cm})$ and weight $(\mathrm{kg})$, as measured using the scale connected to the device, were entered into the computer using the devices default software (Software Version 5.4.1, COSMED USA, Inc.). Subjects were then asked to enter the BodPod ${ }^{\circledR}$, breathe normally, and remain still for the duration of the test.

Bioelectrical impedance spectroscopy (BIS; SFB7, ImpediMed, Queensland, Australia) uses a low voltage electrical current to estimate TBW. Following manufacturer recommendations for preparation and placement, subject were asked to lie supine on a table with separation between the limbs. Leads were connected to four electrodes placed on the right wrist (bisecting the ulnar head), five centimeters distally on the hand, the right ankle (bisecting the malleoli), and five centimeters distally on the foot. The subject was instructed to lie still and breathe normally during the test. This device scans 256 frequencies between the ranges of 4 and $1000 \mathrm{kHz}$. The average of two measurements was recorded for TBW.

Dual-energy x-ray absorptiometry (DEXA; GE Lunar iDXA, GE Medical Systems Ultrasound \& Primary Care Diagnostics, Madison, WI, USA) was used to estimate total body bone mineral content $(\mathrm{BMC})$ and calculate $\mathrm{Mo}(\mathrm{Mo}=\mathrm{BMC}(\mathrm{kg}) \times 1.0436)$. Total body scans were performed by trained DEXA technicians using default software (enCORE Software Version 16). Prior to the scanning, identification code, age, sex, ethnicity, height (in) and weight (lbs) were entered into the computer. The subject was asked to lie down on the DEXA table in the supine position and centered on the table within the scanning area. The subject's shoulders and hips were centered, with hands placed by the side of the legs in a prone position. For those 
wider than the scanning parameter $(n=6)$, the subject was shifted left-of-center to ensure a full scan of the right side of the body and left limbs were estimated from the right limbs, as suggested by the manufacturer. Once positioned, a strap was secured around the ankles for comfort and subjects were instructed to lie still and breathe normally for the duration of the scan (7-13 $\mathrm{min})$. $\underline{\text { Visceral Adipose Tissue }}$

Brightness-mode (B-mode) ultrasound (US) (GE LOGIQ-e, Software version R8.0.7, GE Healthcare, Wisconsin, USA) with standardized settings (Frequency: 4.0 MHz, Gain: 45) was used to quantify VAT. While lying supine, a wide-band convex array ultrasound transducer (GE: C1-5 RS) with transducer gel was applied to the abdomen at the site of the linea alba, $5 \mathrm{~cm}$ proximal to the umbilicus. The depth of the scan was adjusted as necessary to ensure full image capture of visceral adiposity. Once positioned, the subject was asked to take a deep breath in, followed by a relaxed breath out; a still image of the abdomen was captured at the moment of

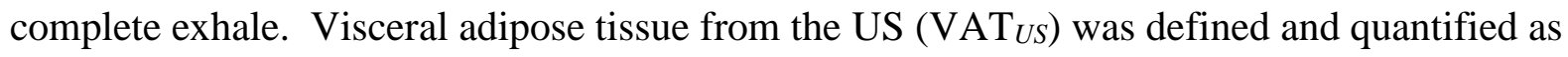
the perpendicular distance between the interior border of the rectus abdominis and the posterior wall of the aorta [35]. The average of two measurements were recorded as $\mathrm{VAT}_{U S}$. Test-retest reliability for $\mathrm{VAT}_{U S}$ produced an $\mathrm{ICC}=0.99, \mathrm{SEM}=0.35 \mathrm{~cm}$, and minimum difference $(\mathrm{MD})=0.69 \mathrm{~cm}$.

Dual-energy x-ray absorptiometry was also used to estimate VAT mass (VAT $\left.\mathrm{VAXXA}_{\text {A }}\right)$. From the previously described total body scan, $\mathrm{VAT}_{D E X A}$ was defined as the automatically selected android region-of-interest set by DEXA software. This region was pre-programmed to quantify abdominal fat spanning between the top of the iliac crest to $20 \%$ of the distance from the top of the iliac crest to the base of the skull (Figure 3B) [69]. 


\section{$\underline{\text { Resting metabolic rate }}$}

Resting metabolic rate and RER rest were evaluated using a ventilated canopy with indirect calorimetry. Prior to measurements, the hood was calibrated to manufacture's standards with a gas mixture of known concentrations of oxygen and carbon dioxide. While lying in a supine position, subjects were fitted with the ventilated canopy. The canopy was placed over the subjects head and secured comfortably around the neck and arms, ensuring that no air could penetrate the sealed canopy. Subjects were asked to relax and breathe normally for 30 minutes. Respiratory gases, oxygen uptake, and carbon dioxide production, were analyzed breath-bybreath with a metabolic cart (TrueOne 2400, ParvoMedics, Inc., Sandy, UT). During the first five minutes of the test, the dilution rate was adjusted until the fraction of expired carbon dioxide was between $1.0-1.2 \%$. This portion of the test was excluded to account for normalization and

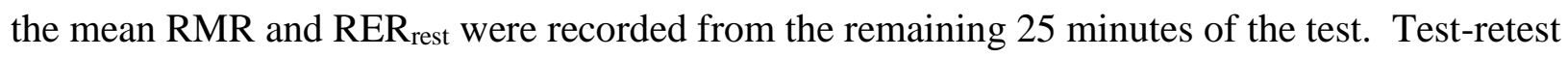
reliability for RMR from our lab produced an ICC=0.94, SEM=125.6 kcal $\cdot$ day $^{-2}$ and MD=244.3 $\mathrm{kcal}^{\circ}$ day $^{-2}$, and RER rest was ICC $=0.83, \mathrm{SEM}=0.03$ and $\mathrm{MD}=0.05$.

\section{$\underline{\text { Blood Lipid and Hormone Analysis }}$}

All blood draws were done in the Applied Physiology Lab by an individual trained in phlebotomy in accordance with bloodborne pathogen precautions established by UNC's Occupational Health Services. A $4 \mathrm{ml}$ sample from the region of the antecubital vein was collected and analyzed using established enzymatic assays for fasting blood glucose (GLUC), total cholesterol (TC), triglycerides (TRG), high-density lipoproteins (HDL), low-density lipoproteins (LDL), insulin, and leptin. Samples were analyzed by the Biobehavioral Lab (Chapel Hill, NC). Lipid profiles were analyzed within 15 minutes of the draw. 


\section{$\underline{\text { Salivary Hormone Analysis }}$}

A 1.0-2.0 ml saliva sample was obtained and analyzed for estradiol and cortisol concentrations. To avoid blood contamination, subjects avoided brushing their teeth for 45 minutes prior and undergoing dental work for 48 hours prior to sample collection. Immediately upon arrival and prior to sample collection, subjects rinsed their mouth with water to remove any residues. All samples were kept frozen at $-20^{\circ} \mathrm{C}$ until analysis. Samples were analyzed by the Biobehavioral Lab (Chapel Hill, NC) using established enzymatic assays.

\section{$\underline{\text { Steady-state cardiorespiratory assessment }}$}

A steady-state cardiorespiratory assessment was used to evaluate RER during exercise

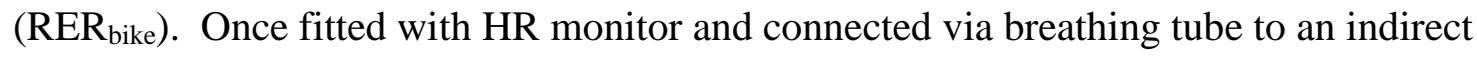
calorimetry system (TrueMax 2400, Parvo Medics, Salt Lake City, UT), individuals were allowed a three minute warm-up on a cycle ergometer (Lode, Gronigen, The Netherlands) at a self-selected speed and workload of 20W. After three minutes, the workload was manually increased until heart rate (HR) correlated to 50-60\% heart rate reserve (HRR). Once HR was within five beats per minute of the target HRR, respiratory gases were analyzed breath-by-breath via open-circuit spirometry for 20 minutes to measure RER bike. Heart rate was monitored throughout the test using a Polar heart rate monitor (Polar FT1, Polar USA, Port Washington, NT, USA) and workload was adjusted throughout the test as necessary to maintain 50-60\% HRR.

Heart rate reserve was calculated using the Karvonen formula $\left(H R R=\left[H R_{\max }-\mathrm{HR}_{\text {rest }}\right] \mathrm{x}\right.$ \%intensity $\left.+\mathrm{HR}_{\text {rest }}\right)$ where $\mathrm{HR}_{\max }$ is age predicted maximal $\mathrm{HR}\left(\mathrm{HR}_{\max }=220-\right.$ age $)$ and $\mathrm{HR}_{\text {rest }}$ is resting HR, the average HR achieved during the resting metabolic rate test. To assess potential metabolic inflexibility, change in respiratory exchange ratio $(\triangle \mathrm{RER})$ was calculated as the difference between RER $_{\text {bike }}$ and RER $_{\text {rest }}$. 


\section{$\underline{\text { Statistical Analysis }}$}

This study was a portion of a larger study assessing the effects of a breakfast meal replacement on body composition and metabolic characteristics of overweight and obese adults. Power calculations for this study were conducted using nQuery version 7.0. Using mean and standard deviation values from a similar population [70], a sample of 50 subjects was determined, providing a power of at least $80 \%$ for a repeated measures ANOVA with significance of $\alpha=0.05$. This sample size also accounted for a loss of a predicted five subjects (10\%). Power calculations for the larger study were calculated for a higher order statistical calculation and provide sufficient power (>80\%) for the current study.

To characterize metabolic health, each metabolic variable was stratified into categories associated with accepted reference ranges. Frequency rates for each category were calculated within each variable. Individuals were categorized as overweight $\left(25-29.9 \mathrm{~kg} \cdot \mathrm{m}^{-2}\right)$, obese $(30-$ $\left.34.9 \mathrm{~kg} \cdot \mathrm{m}^{-2}\right)$, obese II $\left(35-39.9 \mathrm{~kg} \cdot \mathrm{m}^{-2}\right)$, or obese III $\left(\geq 40.0 \mathrm{~kg} \cdot \mathrm{m}^{-2}\right)$ to assess metabolic disease risk based on BMI [71]. Based on \%fat, individuals were categorized as moderate $(\mathrm{M}<25 \%$; $\mathrm{F}<38 \%)$ or high risk $(\mathrm{M} \geq 25 \% ; \mathrm{F} \geq 38 \%)$ [72]. High TRG, low HDL, high GLUC, and $\mathrm{VAT}_{U S}$ were used characterize individuals based on metabolic syndrome risk factors [73]; $\mathrm{VAT}_{U S}$ was substituted for the traditional waist circumference risk factor. Individuals were further characterized based on other markers of metabolic health. Lean mass index $\left(\mathrm{LMI} ; \mathrm{LM}(\mathrm{kg}) \cdot \mathrm{m}^{-2}\right)$ was used to stratify LM measured by DEXA based on normative values for sex, race, and age [74]. Visceral adipose tissue thickness was stratified as low $(<7 \mathrm{~cm})$, moderate $(\mathrm{M}=7-9 \mathrm{~cm} ; \mathrm{W}=7$ $8 \mathrm{~cm})$, or high $(\mathrm{M}>9 \mathrm{~cm} ; \mathrm{W}>8 \mathrm{~cm})[35]$. Resting metabolic rate was stratified as low $(<125.6$ $\mathrm{kcal} / \mathrm{d}$ below predicted), normal $( \pm 125.6 \mathrm{kcal} / \mathrm{d}$ of predicted $)$, or high $(>125.6 \mathrm{kcal} / \mathrm{d}$ above predicted). Resting metabolic rate stratification was based on the difference between predicted 
and measured metabolic rate (predicted - measured) using the Harris-Benedict prediction equation [75]. Resting RER was stratified as low $(<0.82)$, normal $(0.85 \pm 0.03)$ or high $(>0.88)$.

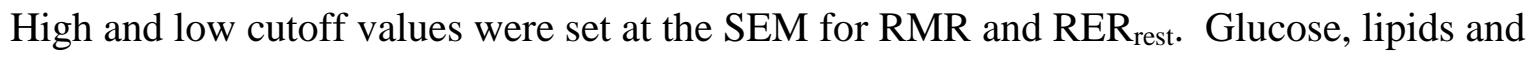
hormones were stratified according to standard clinical metabolic diagnoses (Table 3) [1, 76-80]. Estradiol and cortisol stratification was based off of Salimetrics reference data. Insulin resistance was assessed by calculating HOMA-IR as described by Levy et al. (1998) [79, 80]. Individuals were categorized as normal $(\leq 2.5)$ or high $(>2.5)$ according to their calculated HOMA-IR [81, 82].

A Pearson product-moment correlation was used to identify significant relationships between body composition (FM, LM, \%fat, VAT), RMR, RER rest $_{\text {, RER }}$ bike, GLUC, lipids, and hormones (insulin, leptin, estrogen, cortisol), and in addition to relationships between leptin, RMR, RER rest $_{\text {, and }}$ RER $_{\text {bike. }}$ Separate Pearson product-moment correlations were used to identify significant relationships by sex between these same variables.

A one-way analysis of variance (ANOVA) was used to evaluate significant differences in RMR, RER rest $_{\text {, RER }}$ bike, GLUC, lipids, and hormones (insulin, leptin, estrogen, cortisol), and between males and females. A separate one-way ANOVA was used to evaluate differences in these same variables between overweight and obese individuals (overweight $=\mathrm{BMI}<30.0$, Obese $=\mathrm{BMI} \geq 30.0$ ). Separate analysis of co-variances (ANCOVA) were used to evaluate significant differences in RMR, RER rest $_{\text {, RER }}$ bike, GLUC, lipids, and hormones (insulin, leptin, estrogen, cortisol) between males and females and overweight and obese individuals when covarying for differences in LM.

A multiple regression analysis was used to assess the variances in body composition (FM, LM, \%fat, VAT) and RMR, RER ${ }_{\text {rest }}$, and RER bike using standard clinical measures (GLUC, 
lipids, insulin, leptin, estrogen, cortisol). Visceral adipose tissue (VAT $\left.\mathrm{VAS}_{U}\right)$ was included as a potentially feasible clinical factor when evaluating variance in FM, LM, and \%fat. All statistical analyses were completed using SPSS (Version 21, IBM, Armonk, NY, USA), using a significance of $\alpha=0.05$ to determine statistical significance. 


\section{CHAPTER IV}

\section{RESULTS}

Based on BMI and \%fat categorization, all individuals were considered to be at an increased metabolic disease risk (Table 2). Twenty-two (45.3\%) individuals were considered to be at a very high risk, with a $\mathrm{BMI} \geq 35 \mathrm{~kg} \cdot \mathrm{m}^{-2}$. All individuals were considered to be at a high risk based on \%fat, except for one who was considered to be at a moderate risk, but was borderline high risk (F; 37.6\%fat). When evaluating the combined risk factors for metabolic syndrome (abdominal obesity, elevated TRG, low HDL, and elevated fasting glucose), 32 individuals $(71.1 \%)$ had no more than one risk factor (Table 2). Only one individual had three risk factors $(2.2 \%)$, meeting the criteria for metabolic syndrome. When additional novel factors

were used to evaluate metabolic risk (LMI, RMR, RER rest, TC, LDL, HOMA-IR) the frequency of individuals with three or more risk factors increased to $48.8 \%$ ( $n=22)$. Frequencies of individual metabolic risk factors are presented in Table 3.

\section{Body Composition}

Research Question: Is there a relationship between total and regional body composition, RMR, RER $_{\text {rest }}$, RER $_{\text {bike, }}$ glucose, lipids, and hormones in overweight and obese adults?

Research Question: Are there differences in total and regional body composition, RMR, $\mathrm{RER}_{\text {rest }}, \mathrm{RER}_{\text {bike, }}$ glucose, lipids, and hormones between overweight and obese adults? 
Fat Mass

For the entire group FM ranged from $24.54-75.05 \mathrm{~kg}$. For the entire group, FM was not significantly correlated with $\operatorname{RMR}(p=0.163), \operatorname{RER}_{\text {rest }}(\mathrm{p}=0.711), \mathrm{RER}_{\text {bike }}(\mathrm{p}=0.691)$, or $\Delta \mathrm{RER}$ $(\mathrm{p}=0.918)$. Fat mass was significantly positively correlated with insulin $(\mathrm{p}=0.000, \mathrm{r}=0.665)$, estradiol $(p=0.003, r=0.417)$, and leptin $(p=0.000, r=0.654)$, but not cortisol $(p=0.812)$. There were no significant correlations between FM, TC ( $\mathrm{p}=0.742)$, TRG $(\mathrm{p}=0.168), \operatorname{HDL}(\mathrm{p}=0.534)$, LDL $(\mathrm{p}=0.458)$, or GLUC $(\mathrm{p}=0.734)$. There was also no correlation between FM and $\mathrm{VAT}_{U S}$ $(\mathrm{p}=0.264, \mathrm{r}=0.163)$.

When comparing differences between overweight and obese individuals, obese individuals had greater FM, than overweight individuals $(\mathrm{p}<0.001 ; \mathrm{OB}=42.50 \pm 10.63 \mathrm{~kg}$; OW= $30.15 \pm 4.00 \mathrm{~kg}$ ). When comparing differences between males and females, females had significantly greater $\mathrm{FM}$ than males $(\mathrm{p}=0.006 ; \mathrm{F}=43.14 \pm 11.03 \mathrm{~kg} ; \mathrm{M}=34.80 \pm 8.83 \mathrm{~kg})$. In males, greater FM was positively associated with $\operatorname{RER}_{\text {rest }}(\mathrm{p}=0.028, \mathrm{r}=0.459)$, insulin $(\mathrm{p}=0.004$, $\mathrm{r}=0.580)$, estradiol $(\mathrm{p}=0.003, \mathrm{r}=0.417)$, and leptin $(\mathrm{p}=0.000, \mathrm{r}=0.765)$; associations with RMR approached significance $(\mathrm{p}=0.061, \mathrm{r}=0.396)$. In females, greater FM was associated with greater $\operatorname{VAT}_{U S}(\mathrm{p}=0.077, \mathrm{r}=0.353)$, higher RMR $(\mathrm{p}=0.028, \mathrm{r}=0.459)$, insulin $(\mathrm{p}<0.001, \mathrm{r}=0.704)$, and leptin $(\mathrm{p}=0.004, \mathrm{r}=0.587)$.

\section{Lean Mass}

For the entire group LM ranged from 39.10 - $85.48 \mathrm{~kg}$. When evaluating LM based on LMI, 33 individuals had "normal” LM (LM: 39.10 - $74.50 \mathrm{~kg}$ ), while 16 individuals had "high" LM (LM: $46.45-85.48 \mathrm{~kg}$ ). Five individuals, all of whom were females, had a LMI greater than two standard deviations ( $>97^{\text {th }}$ percentile; LM: $56.05-75.15 \mathrm{~kg}$ ), suggesting higher than 
average LM for sex, age, and race (Figure 5). These five females all demonstrated a \%fat of $>40 \%$ and had normal metabolic rates, TC, TRG, and GLUC. Four of the five also had normal LDL and low cortisol levels. No individuals were categorized with 'low' LM. Lean mass was significantly positively correlated with $\operatorname{VAT}_{U S}(\mathrm{p}=0.024, \mathrm{r}=0.323)$ and $\mathrm{RMR}(\mathrm{p}<0.001, \mathrm{r}=0.900)$, but not $\operatorname{RER}_{\text {rest }}(\mathrm{p}=0.080), \operatorname{RER}_{\text {bike }}(\mathrm{p}=0.337)$, or $\Delta \operatorname{RER}(\mathrm{p}=0.918, \mathrm{p}=0.015)$. There was a significant positive correlation between LM and insulin ( $\mathrm{p}=0.075, \mathrm{r}=0.268)$, a negative correlation with leptin $(\mathrm{p}=0.026, \mathrm{r}=-0.332)$, and no relationship with cortisol $(\mathrm{p}=0.854, \mathrm{r}=$ 0.027) or estradiol ( $\mathrm{p}=0.407, \mathrm{r}=0.121$ ). Lean mass was positively correlated with TRG ( $\mathrm{p}=0.009$, $\mathrm{r}=0.384$ ) and negatively correlated with HDL ( $\mathrm{p}=0.003, \mathrm{r}=-0.438$ ). There was no correlation with TC ( $\mathrm{p}=0.502, \mathrm{r}=0.103)$, LDL ( $\mathrm{p}=0.440, \mathrm{r}=0.118)$ or GLUC $(\mathrm{p}=0.121, \mathrm{r}=0.235)$.

When comparing differences between overweight and obese, obese individuals had greater LM than overweight individuals $(\mathrm{p}=0.010 ; \mathrm{OB}=61.31 \pm 11.64 \mathrm{~kg}$; $\mathrm{OW}=51.42 \pm 10.70$ $\mathrm{kg}$ ). When comparing differences between males and females, males had significantly greater LM than females $(\mathrm{p}<0.0001 ; \mathrm{M}=67.35 \pm 8.54 \mathrm{~kg} ; \mathrm{F}=51.02 \pm 9.35 \mathrm{~kg})$. In males, greater $\mathrm{LM}$ was positively associated with $R M R(p<0.001, r=0.871), R_{\text {rest }}(p=0.039, r=0.433)$, insulin $(\mathrm{p}=0.005, \mathrm{r}=0.562)$, estradiol $(\mathrm{p}=0.002 \mathrm{r}=0.605)$, and TRG $(\mathrm{p}=0.057, \mathrm{r}=0.402)$; associations with HDL approached significance $(\mathrm{p}=0.055, \mathrm{r}=-0.406)$. In females, greater LM was positively associated with RMR ( $\mathrm{p}<0.001, \mathrm{r}=0.871)$ and insulin $(\mathrm{p}=0.017, \mathrm{r}=0.503)$.

\section{Percent Body Fat}

For the entire group, \%fat ranged from $25.42-52.78 \%$. For the entire group, \%fat was not correlated with $\mathrm{VAT}_{U S}(\mathrm{p}=0.531)$. Percent body fat was negatively correlated with RMR $(\mathrm{p}=0.001, \mathrm{r}=-0.467)$, but not $\mathrm{RER}_{\text {rest }}(\mathrm{p}=0.377), \mathrm{RER}_{\text {bike }}(\mathrm{p}=0.826)$, or $\triangle \mathrm{RER}(\mathrm{p}=0.652)$. Percent 
body fat was positively correlated with insulin $(\mathrm{p}=0.013, \mathrm{r}=0.369)$, estradiol $(\mathrm{p}=0.048, \mathrm{r}=0.284)$, and leptin $(\mathrm{p}=0.000, \mathrm{r}=0.829)$, but not with cortisol $(\mathrm{p}=0.923)$. Percent body fat was positively correlated with HDL $(p=0.006, r=0.404)$ and negatively correlated with TRG $(p=0.003, r=-$ 0.426); there was no correlation with TC ( $\mathrm{p}=0.897) \operatorname{LDL}(\mathrm{p}=0.716)$, or GLUC ( $\mathrm{p}=0.486)$.

There was no difference in \%fat between overweight and obese individuals $(\mathrm{p}=0.146)$. When comparing differences between males and females, females had significantly higher \%fat than males $(\mathrm{p}<0.001 ; \mathrm{F}=45.48 \pm 4.12 \% ; \mathrm{M}=33.78 \pm 4.76 \%)$. In males, a greater \%fat was positively associated with leptin $(\mathrm{p}<0.001, \mathrm{r}=0.700)$. In females, a greater $\%$ fat was positively associated with insulin $(\mathrm{p}=0.011, \mathrm{r}=0.531)$, leptin $(\mathrm{p}=0.001, \mathrm{r}=0.635)$, and LDL $(\mathrm{p}=0.031$, $\mathrm{r}=0.460)$; associations with $\operatorname{RER}_{\text {rest }}(\mathrm{p}=0.051, \mathrm{r}=-0.387)$ and $\mathrm{TC}(\mathrm{p}=0.077, \mathrm{r}=0.385)$ approached significance.

\section{Visceral Adipose Tissue}

Research Question: Are there differences in relationships between VAT and markers of metabolic health when measured via B-mode US or dual-energy x-ray absorptiometry (DEXA)?

For the entire group, $\mathrm{VAT}_{U S}$ ranged from $2.21-10.55 \mathrm{~cm}$. Thirty-six individuals $(73.5 \%)$ were considered at low CVD risk $(2.21-6.77 \mathrm{~cm}), 10$ were at a moderate risk $(7.32-$ $8.58 \mathrm{~cm})$, and three were at a high risk $(8.83-10.55 \mathrm{~cm})$. For the entire group, there was no significant correlation between $\operatorname{VAT}_{U S}, \operatorname{RMR}(\mathrm{p}=0.078), \operatorname{RER}_{\text {rest }}(\mathrm{p}=0.783), \operatorname{RER}_{\text {bike }}(\mathrm{p}=0.797)$, or $\triangle$ RER ( $\mathrm{p}=0.967)$. There was no significant correlation between $\mathrm{VAT}_{U S}$, insulin $(\mathrm{p}=0.143)$, cortisol $(p=0.078)$, estradiol $(p=0.516)$, or leptin $(p=0.919)$. There was no significant correlation between $\operatorname{VAT}_{U S}, \operatorname{GLUC}(\mathrm{p}=0.297), \mathrm{TC}(\mathrm{p}=0.411), \mathrm{TRG}(\mathrm{p}=0.975), \operatorname{HDL}(\mathrm{p}=0.136)$, and LDL $(\mathrm{p}=0.130)$. 
There were no significant difference in $\mathrm{VAT}_{U S}$ between overweight and obese individuals $(\mathrm{p}=0.959)$. Differences between males and females approached significance $(\mathrm{p}=0.053)$, with males having more $\mathrm{VAT}_{U S}$ than females $(\mathrm{M}=6.53 \pm 1.93 \mathrm{~cm} ; \mathrm{F}=5.53 \pm 1.62 \mathrm{~cm})$. In males, there was no association between $\mathrm{VAT}_{U S}$ and metabolic factors. In females, $\mathrm{VAT}_{U S}$ was positively associated with insulin ( $\mathrm{p}=0.009, \mathrm{r}=0.545)$ and leptin $(\mathrm{p}=0.012, \mathrm{r}=0.523)$. When accounting for differences in LM between males and females, there was no significant difference in $\mathrm{VAT}_{U S}$ $(\mathrm{p}=0.570)$.

When measured by DEXA, VAT $\mathrm{VEXX}_{\text {A }}$ was positively associated with $\mathrm{RMR}(\mathrm{p}<0.001$, $\mathrm{r}=0.577)$, insulin $(\mathrm{p}=0.002, \mathrm{r}=0.455)$, and estradiol $(\mathrm{p}=0.075, \mathrm{r}=0.256)$ and negatively associated with HDL ( $\mathrm{p}=0.024, \mathrm{r}=-0.336)$; associations with $\mathrm{RER}_{\mathrm{rest}}(\mathrm{p}=0.062, \mathrm{r}=0.269), \mathrm{TC}(\mathrm{p}=0.088$, $\mathrm{r}=0.257)$, and LDL ( $\mathrm{p}=0.062, \mathrm{r}=0.280$ ) approached significance. There was not a significant difference in $\mathrm{VAT}_{D E X A}$ between overweight and obese individuals $(\mathrm{p}=0.142)$. When comparing differences between males and females, males had greater $\mathrm{VAT}_{D E X A}$ than females $(\mathrm{p}=0.011$; $\mathrm{M}=3.4 \pm 1.7 \mathrm{lbs} ; \mathrm{F}=2.3 \pm 1.1 \mathrm{lbs})$. In males, $\mathrm{VAT}_{D E X A}$ was positively associated with $\mathrm{RER}_{\text {rest }}$ $(\mathrm{p}=0.029, \mathrm{r}=0.456)$, insulin $(\mathrm{p}<0.001, \mathrm{r}=0.674), \mathrm{TC}(\mathrm{p}=0.010, \mathrm{r}=0.525)$, and LDL $(\mathrm{p}=0.037, \mathrm{r}=$ 0.437); associations with RMR ( $\mathrm{p}=0.076, \mathrm{r}=0.377)$ and estradiol $(\mathrm{p}=0.061, \mathrm{r}=0.397)$ approached significance. In females, $\mathrm{VAT}_{D E X A}$ was positively associated with $\mathrm{RMR}(\mathrm{p}<0.001, \mathrm{r}=0.654)$, insulin $(\mathrm{p}=0.004, \mathrm{r}=0.588)$, and estradiol $(\mathrm{p}=0.030, \mathrm{r}=0.425)$ and negatively associated with HDL $(\mathrm{p}=0.018, \mathrm{r}=-0.499)$.

\section{Metabolic Rate}

Research Question: Are there differences in RMR, RER rest $_{\text {, }}$ RER $_{\text {bike, }}$ glucose, lipids, and hormones between men and women, when accounting for dietary intake and body composition? 
For the entire group, RMR ranged from $1292-2466 \mathrm{kcal} / \mathrm{d}$. Twenty-two individuals (44.9\%) had lower than predicted RMR, while three individuals had higher than predicted RMR (Figure 6). When comparing differences between overweight and obese, obese individuals had a higher RMR than overweight individuals $(\mathrm{p}=0.002 ; \mathrm{OB}=1894.75 \pm 301.60 \mathrm{kcal} / \mathrm{d}$; OW $=$ $1587.46 \pm 216.45 \mathrm{kcal} / \mathrm{d}$ ); when controlling for differences in LM, there was no significant difference between overweight and obese individuals ( $\mathrm{p}=0.096$ ). When controlling for body mass, RMR was positively correlated with $\mathrm{LM}(\mathrm{p}<0.001, \mathrm{r}=0.764)$ and negatively correlated with FM ( $p<0.001, r=-0.764)$ and \%fat $(p<0.001, r=-0.758)$; there was no significant correlation with $\mathrm{VAT}_{U S}$ or $\mathrm{VAT}_{D E X A}(\mathrm{p}>0.05)$. When comparing differences between males and females, males had significantly higher RMR than females $(\mathrm{p}<0.001 ; \mathrm{M}=2011.13 \pm 259.01 \mathrm{kcal} / \mathrm{d}$; $\mathrm{F}=1638.15 \pm 242.76 \mathrm{kcal} / \mathrm{d}$ ). When accounting for differences in $\mathrm{LM}$, there was no significant difference in RMR between males and females ( $\mathrm{p}=0.873$ ). When accounting separately for differences in CHO, FAT, PRO, and CAL, males had a higher RMR than females $(\mathrm{p}<0.001)$. When controlling for body mass in males, RMR was positively correlated with $\mathrm{LM}$ ( $\mathrm{p}=0.005$, $\mathrm{r}=0.572)$ and negatively correlated with $\mathrm{FM}(\mathrm{p}=0.005, \mathrm{r}=-0.572)$ and \%fat $(\mathrm{p}=0.006, \mathrm{r}=-0.562)$. When controlling for body mass in females, RMR was negatively correlated with \%fat ( $\mathrm{p}=0.038$, $\mathrm{r}=-0.417)$; relationships with LM and FM approached significance ( $\mathrm{p}=0.057, \mathrm{r}=0.386$ and $\mathrm{p}=0.057, \mathrm{r}=-0.386)$. There was no significant correlation between $\mathrm{VAT}_{U S}$ or $\mathrm{VAT}_{D E X A}$ in males or females $(\mathrm{p}>0.05)$.

For the entire group, $\mathrm{RER}_{\text {rest }}$ ranged from (0.77 - 0.98 a.u.). Eight individuals had a $\mathrm{RER}_{\text {rest }}$ greater than 0.88 a.u., indicating a higher reliance on carbohydrate metabolism at rest compared to 13 individuals who had a RER rest $_{\text {less }}$ than 0.82 indicating greater reliance on fat 
metabolism at rest. There was no significant difference in $\mathrm{RER}_{\text {rest }}$ between overweight and obese individuals $(\mathrm{p}=0.493)$ or between males and females $(\mathrm{p}=0.638)$. When accounting separately for differences in LM, CHO, FAT, PRO, and CAL intake between males and females, there was no significant difference in $\operatorname{RER}_{\text {rest }}(\mathrm{p}>0.05)$.

For the entire group, $\mathrm{RER}_{\text {bike }}$ ranged from 0.85 to 1.19 a.u. Forty-five individuals (91.8\%) individuals had a $\mathrm{RER}_{\text {bike }}$ greater than 0.88 , indicating greater reliance on $\mathrm{CHO}$ during steady-state exercise. There was no significant difference in RER bike between overweight and obese individuals $(\mathrm{p}=0.344)$ between males and females $(\mathrm{p}=0.678)$. When accounting separately for differences in LM, CHO, FAT, PRO, and CAL intake, there was no significant difference in RER $_{\text {bike }}$ between males and females ( $\left.p>0.05\right)$.

For the entire group, $\triangle \mathrm{RER}$ ranged from -0.01 to 0.31 a.u. There was no significant difference in $\triangle$ RER between overweight and obese individuals ( $\mathrm{p}=0.695)$ or between males and females ( $\mathrm{p}=0.964$ ). When accounting separately for differences in LM, CHO, FAT, PRO, and CAL intake, there was no significant difference in $\triangle$ RER between males and females $(\mathrm{p}>0.05)$.

\section{Lipids and glucose}

Average lipid and GLUC values for the entire group and between males and females are presented in Table 1 . Males had significantly higher TRG ( $\mathrm{p}=0.004)$, while females had significantly higher HDL $(\mathrm{p}=0.002)$. There were no significant difference between males and females for TC $(\mathrm{p}=0.320)$, LDL $(\mathrm{p}=0.274)$ or GLUC $(\mathrm{p}=0.086)$. There was no significant difference in blood lipids or GLUC between overweight and obese individuals ( $p>0.05$ ). When accounting for differences in LM, there was no significant difference in blood lipids or GLUC between males and females $(p>0.05)$. 


\section{$\underline{\text { Hormones }}$}

Research Question: Is there a relationship between leptin, RMR and RER $_{\text {rest }}$, RER $_{\text {bike? }}$ ?

Average hormonal values for the entire group and between males and females are presented in Table 1. All individuals had normal or high leptin levels (Mean: $36.09 \pm 28.95$ ng/mL; Range: 3.90 - 103.17 ng/mL). There was a non-significant negative correlation between leptin and RMR, $(p=0.084, r=-0.261)$; there was no correlation between leptin, $R R_{\text {rest }}$ $(p=0.700), \operatorname{RER}_{\text {bike }}(p=0.941)$, or $\triangle \operatorname{RER}(p=0.837)$. Differences in leptin between overweight and obese individuals approached significance with obese individuals having higher leptin levels $(\mathrm{p}=0.053 ; \mathrm{OB}=41.09 \pm 31.03 \mathrm{ng} / \mathrm{mL} ; \mathrm{OW}=22.33 \pm 16.41 \mathrm{ng} / \mathrm{mL})$. Females had significantly higher leptin than males $(\mathrm{p}<0.0001 ; \mathrm{F}=58.11 \pm 25.23 \mathrm{ng} / \mathrm{mL} ; \mathrm{M}=15.02 \pm 10.93 \mathrm{ng} / \mathrm{mL})$. When accounting for differences in LM, females had greater leptin than males (Mean difference \pm SEM; $1.09 \pm 0.28 \mathrm{ng} / \mathrm{mL})$.

Average cortisol levels were $0.28 \pm 0.15 \mu \mathrm{g} / \mathrm{dL}(0.08-0.71 \mu \mathrm{g} / \mathrm{dL})$. No individuals had high cortisol levels, but seven individuals were considered to have low cortisol levels based on sex and age $(0.08-0.25 \mu \mathrm{g} / \mathrm{dL})$. Difference in cortisol between overweight and obese individuals approached significance $(\mathrm{p}=0.063)$ with obese individuals having higher cortisol $(0.31 \pm 0.16 \mu \mathrm{g} / \mathrm{dL})$ than overweight individuals $(0.23 \pm 0.10 \mu \mathrm{g} / \mathrm{dL})$. There was no significant difference in cortisol levels between males and females $(\mathrm{p}=0.784)$. When accounting for differences in LM, there was no significant difference in cortisol levels between males and females $(\mathrm{p}=0.589)$.

Average estradiol was $1.99 \pm 0.82 \mathrm{pg} / \mathrm{mL}$; eleven individuals had low estradiol levels $(0.63-1.33 \mathrm{pg} / \mathrm{mL})$, eight of whom were males. Three individuals had high estradiol levels 
$(3.13-5.46 \mathrm{pg} / \mathrm{mL})$, two of whom were also males. Obese individuals had higher estradiol levels than overweight individuals ( $\mathrm{p}=0.035 ; \mathrm{OB}=2.14 \pm 0.85 \mathrm{pg} / \mathrm{mL} ; \mathrm{OW}=1.58 \pm 0.57 \mathrm{pg} / \mathrm{mL}$ ). Differences in estradiol between males and females approached significance $(\mathrm{p}=0.052)$, with females having higher estradiol levels than males $(\mathrm{F}=2.20 \pm 0.81 \mathrm{pg} / \mathrm{mL} ; \mathrm{M}=1.75 \pm 0.76 \mathrm{pg} / \mathrm{mL})$.

Average insulin was $9.68 \pm 7.36 \mathrm{uIU} / \mathrm{mL}$. There was no significant difference in insulin between overweight and obese adults $(\mathrm{p}=0.143)$. There was no significant difference in insulin between males and females ( $\mathrm{p}=0.263)$, but when accounting for differences in LM, males had significantly higher insulin levels than females $(\mathrm{p}=0.001)$ (Mean difference \pm SEM: $8.74 \pm 2.52$ $\mathrm{uIU} / \mathrm{mL})$.

\section{$\underline{\text { Regression Analysis }}$}

Research Question: Will variances in total and regional body composition, RMR, RER rest, $\mathrm{RER}_{\text {bike, }}$, and $\triangle \mathrm{RER}$ be explained by blood and hormonal markers of metabolic health?

Standard clinical measures (GLUC, lipids, insulin, leptin, estrogen, cortisol) were used as predictors for non-standard clinical measures (FM, LM, \%fat, VAT, RMR, RER rest, $_{\text {RER }}$ bike, $\triangle \mathrm{RER}$ ). For body composition: $59.8 \%$ of the variance in FM was explained by insulin ( $\mathrm{p}<0.001$, $\beta=0.681)$ and leptin $(p<0.001, \beta=0.166)(p=0.000, r=0.773, r 2=0.598) ; 72.4 \%$ of the variance in LM was explained by HDL $(\mathrm{p}=0.009, \beta=-0.348)$ and $\mathrm{VAT}_{U S}(\mathrm{p}=0.050, \beta=1.813)(\mathrm{p}=0.002$, $\mathrm{r}=0.851, \mathrm{r} 2=0.724) ; 72.4 \%$ of the variance in $\%$ fat was explained by leptin $(\mathrm{p}<0.001, \beta=0.187)$ and HDL $(\mathrm{p}=0.022, \beta=0.108)(\mathrm{p}=0.000, \mathrm{r}=0.851, \mathrm{r} 2=0.724)$; no standard clinical measures significantly explained the variances in $\mathrm{VAT}_{U S}$, compared to $28.9 \%$ of the variance in $\mathrm{VAT}_{D E X A}$ explained by insulin $(p=0.003, \beta=0.089)$ and TRG $(p=0.033, \beta=0.006)$. 
In males, $60.2 \%$ of the variance in FM was explained by leptin $(\beta=0.627)(\mathrm{p}=0.000$, $\mathrm{r}=0.766, \mathrm{r} 2=0.602) ; 36.6 \%$ of the variance in $\mathrm{LM}$ was explained by estradiol $(\beta=6.658)(\mathrm{p}=0.002$, $\mathrm{r}=0.605, \mathrm{r} 2=0.366) ; 64.3 \%$ of the variance in $\%$ fat was explained by leptin $(\mathrm{p}<0.001, \beta=0.320)$ and HDL ( $\mathrm{p}=0.008, \beta=0.237)(\mathrm{p}=0.000, \mathrm{r}=0.802, \mathrm{r} 2=0.643)$; no standard clinical measures significantly explained the variances in $\mathrm{VAT}_{U S}$. In females, $49.6 \%$ of variances in $\mathrm{FM}$ were explained by insulin $(\beta=0.870)(\mathrm{p}=0.000, \mathrm{r}=0.704, \mathrm{r} 2=0.496) ; 25.3 \%$ of the variance in $\mathrm{LM}$ was explained by insulin $(\beta=0.532)(\mathrm{p}=0.000, \mathrm{r}=0.704, \mathrm{r} 2=0.496) ; 55.0 \%$ of the variance in $\%$ fat was explained by leptin $(\mathrm{p}=0.001, \beta=0.085)$ and $\mathrm{LDL}(\mathrm{p}=0.022, \beta=0.037)(\mathrm{p}=0.001, \mathrm{r}=0.742$, $\mathrm{r} 2=0.550) ; 29.7 \%$ of the variance in $\mathrm{VAT}_{U S}$ was explained by insulin $(\beta=0.090)(\mathrm{p}=0.009$, $\mathrm{r}=0.545, \mathrm{r} 2=0.297)$.

For metabolic rate: $18.4 \%$ of the variances in RMR were explained by HDL $(\beta=-10.255)$ $(\mathrm{p}=0.003, \mathrm{r}=0.429, \mathrm{r} 2=0.184) ; 11.4 \%$ of the variance in $\mathrm{RER}_{\text {rest }}$ was explained by HDL $(\beta=$ $0.001)(\mathrm{p}=0.024 ; \mathrm{r}=0.337 ; \mathrm{r} 2=0.114) ; 14.7 \%$ of the variance in $\mathrm{RER}_{\text {bike }}$ was explained by estradiol $(\beta=0.028)(\mathrm{p}=0.005, \mathrm{r}=0.166, \mathrm{r} 2=0.147) ; 12.0 \%$ of the variance in $\triangle \mathrm{RER}$ was explained by estradiol $(\beta=0.026)(\mathrm{p}=0.020, \mathrm{r}=347, \mathrm{r} 2=0.120)$.

In males, $42.5 \%$ of the variance in RMR was explained by estradiol $(\beta=216.977)$ $(\mathrm{p}=0.001, \mathrm{r}=0.649, \mathrm{r} 2=422) ; 27.5 \%$ of the variances in $\mathrm{RER}_{\text {rest }}$ was explained by insulin $(\beta=0.004)(p=0.010, r=525, r 2=0.275) ; 24.0 \%$ of the variance in $R^{2} R_{b i k e}$ was explained by estradiol $(\beta=0.041)(\mathrm{p}=0.018, \mathrm{r}=0.490, \mathrm{r} 2=240)$; no standard clinical measures significantly explained the variances in $\triangle R E R$. In females, $32.5 \%$ of the variance in RMR was explained by insulin $(\beta=15.353)(\mathrm{p}=0.006, \mathrm{r}=0.570, \mathrm{r} 2=0.325) ; 19.8 \%$ of the variance in $\mathrm{RER}_{\text {rest }}$ was explained by TC $(\beta=-0.001)(\mathrm{p}=0.038, \mathrm{r}=0.445, \mathrm{r} 2=0.198) ; 18.8 \%$ of the variance in $\mathrm{RER}_{\text {bike }}$ was explained 
by estradiol $(\beta=0.027)(p=0.044, r=0.434, r 2=0.188)$; no standard clinical measures significantly explained the variances in $\triangle R E R$. 


\section{CHAPTER V}

\section{DISCUSSION}

Metabolic dysfunction is commonly associated with obesity, excess VAT, dyslipidemia, insulin resistance, and hormonal imbalances $[8,73,83]$. While blood lipids, GLUC, and insulin levels are common indicators of metabolic dysfunction, not all obese individuals have dyslipidemia or insulin resistance, despite excess adiposity $[9,10,84]$. Other components of body composition, such as LM and VAT, have been shown to have strong influences on metabolic factors [12, 13, 30, 83, 85], yet are not assessed using common clinical measures such as BMI and waist circumference. Further, in the absence of dyslipidemia or insulin resistance, other measures such as RMR and RER, may provide early indication of metabolic dysfunction. Results of the current study indicate that FM alone was not significantly correlated with traditional markers of metabolic health (blood lipids and GLUC) in otherwise healthy overweight and obese adults, but may be linked with hormonal profiles, showing positive correlations with insulin, leptin, and estradiol. Fat distribution however, may have stronger associations with metabolic dysfunction. Women with greater FM tended to have more $\mathrm{VAT}_{U S}$ which was significantly correlated with higher insulin and leptin levels. In males, $\mathrm{VAT}_{U S}$ was not associated with FM, but $\mathrm{VAT}_{D E X A}$ significantly correlated with $\mathrm{TC}$, $\mathrm{LDL}$, and insulin, potentially placing men at a greater risk for metabolic dysfunction, even in the absence of excess total body fat. While fat distribution has negative associations with metabolic health, LM in the presence of excess FM may have positive benefits [30]. In the present study, a greater \%fat was associated 
with a lower RMR, while greater LM was associated with a higher RMR. Lean mass may be especially important in women with very high \%fat, as those with above average LM in the present study tended to have normal metabolic rates, TC, LDL, TRG, GLUC, and low cortisol levels, though further investigation into these relationships is necessary. Despite $16.3 \%$ of the group exhibiting increased carbohydrate reliance at rest $\left(\mathrm{RER}_{\text {rest }}>0.88\right)$, body composition did not seem to have strong associations with fuel utilization during rest or steady-state, which may implicate the role of diet and exercise in metabolic health.

Obesity based disease risk is often clinically evaluated using BMI. Based on BMI, all individuals in the group were considered at an elevated disease risk. However, when evaluating common risk factors of metabolic syndrome, almost $1 / 3$ of the group displayed no metabolic risk factors indicating that outside of excess body fat, these individuals could be considered to be relatively metabolically healthy at the time of testing. These findings may also indicate that this form of diagnosis may only be identifying individuals who have reached a certain level of metabolic dysfunction. Health based evaluations from BMI do not properly take into account fat distribution or the presence of LM, both of which have significant roles in metabolic health [9, 30]. Traditional metabolic syndrome criteria accounts for the influence of fat distribution on metabolic health, but uses waist circumference as its standard measure which does not differentiate between abdominal subcutaneous and VAT $[73,86]$. Similarly, BMI does not quantify LM which may have important implications for insulin sensitivity and glucose uptake [30, 50]. Metabolic rate and RER may also be early signs of metabolic dysfunction. Low relative metabolic rate and high carbohydrate reliance at rest have been shown to be associated with weight gain $[67,87]$, potentially contributing to the development of metabolic dysfunction. When accounting for other risk factors not evaluated in traditional metabolic syndrome criteria, 
in addition to the traditional criteria, individuals with two or more metabolic risk factors increased from about $29 \%$ to $80 \%$, indicating that consideration of these factors when evaluating metabolic health may be warranted.

Excess adiposity is known to be associated with insulin resistance and dyslipidemia [88], but more recent studies have identified individuals with up to $50 \%$ body fat who have normal insulin sensitivity and blood lipids $[11,84]$. Fat mass has been shown to be positively correlated with insulin resistance, even in normal weight individuals [38]. Further, insulin resistance has been shown to be significantly related to elevated TRG, LDL, and VAT [11]. While results of the current study support clear associations between all indices of excess fat accumulation (FM, \%fat, and VAT) and insulin, FM was not associated with blood lipids or GLUC in males or females. Interestingly, FM was positively associated with $\mathrm{VAT}_{U S}$ in women, but not in men, likely related to differences in hormonal distribution of fat. Hormones such as leptin, estrogen, and cortisol are commonly associated with FM and fat distribution [15]. In the current study, greater FM and \%fat were associated with higher estradiol and leptin, but not cortisol. When separated by sex, FM was associated with greater estradiol in men, but not in women, supporting previous findings of elevated estradiol levels in obese men [23, 24].

Visceral adipose tissue has been repeatedly shown to be associated with increased risk of metabolic syndrome [89-91], having strong associations with insulin resistance, dyslipidemia, and hormonal imbalances in obese and normal weight individuals [35, 90, 92]. One outcome of the current study was to assess relationships between VAT and markers of metabolic health using B-mode US. B-mode US may be a more accurate and affordable method of quantifying VAT especially in clinical settings where the gold standard CT-scan is costly and potentially impractical $[42,43]$. In the current study, $\mathrm{VAT}_{U S}$ ranged from $2.21-10.55 \mathrm{~cm}$ and was 
significantly correlated with insulin and leptin in women. While greater VAT is typically associated with greater metabolic risk in both men and women, Leite et al. (2002) found that a VAT thickness greater than $8 \mathrm{~cm}$ was associated with high risk in women compared to $9 \mathrm{~cm}$ in men. These results, in combination with those of the current study, may indicate that VAT accumulation in women may be a more serious metabolic risk factor.

Quantification of VAT from a total body DEXA scan is another valid alternative to CT [69]. Ultrasound is commonly criticized for having poor reliability, related to differences in measurement technique [36, 93], which is eliminated by the DEXA quantification. Test-retest reliability calculations for $\mathrm{VAT}_{U S}$ in the current study showed good reliability, but when comparing the two methods, $\mathrm{VAT}_{D E X A}$ was significantly correlated with more markers of metabolic health, including insulin and blood lipids, especially in men. Differences in the degree of the association between the two measures may be related to how VAT is quantified by each device. Ultrasound quantifies thickness of VAT within the abdomen and may include organ tissue, while $\mathrm{VAT}_{D E X A}$ is quantified by mass and volume. Both measurements have been shown to be significantly correlated with CT measurements of VAT [42, 69], but differences in VAT quantification should be considered in future research. Nevertheless, both methods still have significant benefits over waist circumference in determining potential cardiometabolic risk [ 35 , 91].

Lean mass is a major site for glucose uptake and substrate oxidation within the body, potentially having a beneficial impact on improving insulin sensitivity, lowering blood lipids, and increasing metabolic rate [29,30]. Contrary to what might be expected, current results showed that greater LM was associated with $\mathrm{VAT}_{U S}$, insulin, TRG, and low HDL. Other studies have noted a similar relationship between greater LM and poor markers of metabolic health $[84$, 
94-96]. One study demonstrated that obese women with less LM had favorable metabolic profiles compared to obese women with unfavorable metabolic profiles [84]. When comparing differences between women with high and low LM, Brochu et al. (2008) found that higher LM was positively associated with insulin and GLUC. As was supported in the current study, obese individuals often have a greater quantity of LM, likely as a result of supporting greater body weight, but may not always have a higher quality of LM [97, 98]. Greater total body fat has been correlated to greater intramuscular fat and may support the indirect relationship between LM, VAT, and insulin in the present study [50, 97, 99]. It should be noted that five individuals in the current study were identified as having above average LM. All were females, and all tended to have normal TC, LDL, TRG, GLUC, and insulin resistance based on HOMA-IR. While this observation cannot be extrapolated to the larger population and muscle quality was not measured, it may support previous findings demonstrating a benefit of LM in an obese population [30]. Due to the concomitant increase in LM with FM, future considerations for muscle quality in this population should be explored.

Lean mass also has an important contribution to metabolic rate and fuel utilization. Lean mass is more metabolically active than FM, with one study showing that LM accounted for up to $63 \%$ of the inter-individual variability in RMR, compared to less than $9 \%$ from FM [100]. In the current study, a higher metabolic rate was associated with greater LM and lower \%fat. Across the entire group, FM was not associated with RMR or RER, however, obese individuals had a higher RMR than overweight individuals. Further FM and $\mathrm{VAT}_{D E X A}$ were associated with a higher RMR in women, suggesting a potential influence of overall greater body size on RMR. Obese individuals often have a higher metabolic rate compared to normal weight individuals by association of having a greater body mass [101]. Conversely, when metabolic rate is evaluated 
relative to LM and FM, some studies suggest obese individuals may actually have a lower RMR $[102,103]$. About $45 \%$ of individuals in the current study had a lower than predicted metabolic rate, compared to only $6 \%$ who had greater than predicted. Similarly, when controlling for body mass, a lower metabolic rate was associated with FM and \%fat suggesting a potential negative association between excess fat and RMR.

Based on the results of the current study, a higher RER rest $_{\text {was associated with greater }}$ LM, FM, and $\mathrm{VAT}_{D E X A}$ and may represent a greater reliance on carbohydrates. Despite influences of body composition on metabolic rate and fuel utilization, RMR and RER are still highly variable between individuals [104]. In the present study, RER values at rest ranged from $0.77-0.98$ a.u., with similar ranges reported from other studies [31, 67]. Some variances in RER have previously been shown to be hormonally influenced [105]. Specifically, leptin, a signal of chronic energy storage, may indirectly alter RMR and fuel utilization [44, 106]. However, no significant relationships between leptin, RMR or RER were found in the current study.

Blood lipid profiles are a common marker of metabolic health and are part of routine assessments in clinical settings. On the other hand, hormonal imbalances can have profound effects on fat distribution, metabolic regulation, hunger, and satiety [15, 19, 44, 107], but are less often evaluated unless a specific health complication arises. Based on results of the current study, hormonal profiles may be better predictors of variances in total and regional body composition than blood lipids and may provide early indication of developing metabolic dysfunction. Across the entire group, leptin and insulin were strong predictors of FM, while insulin and TRG were significant predictors of $\mathrm{VAT}_{D E X A}$, but not $\mathrm{VAT}_{U S}$. Women typically have greater leptin and estradiol levels than men $[17,107]$. However in the current study there was no 
significant difference in estradiol between men and women, which has been previously reported in obese men $[14,23,24]$. Despite potential hormonal activity of adipose tissue, estradiol in the current study was not a significant predictor of variances in FM or $\mathrm{VAT}_{U S}$ in males, but it was a

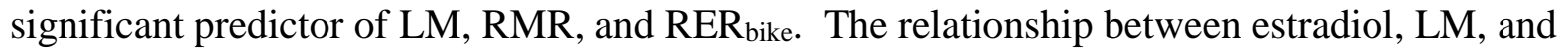
RMR are likely a corresponding association with greater body mass, but the relationship with RER $_{\text {bike }}$ could suggest that relatively high levels of estradiol in men, as was observed in the current study, may have metabolic consequences [108]. In contrast, variances in FM, $\mathrm{VAT}_{U S}$, and RMR in women in the current study were more strongly predicted by insulin, reiterating the more serious implications VAT accumulation may have in women. Previous studies have associated VAT with increased cortisol levels [26, 27], however, cortisol was not a strong predictor of $\mathrm{VAT}_{U S}$ or $\mathrm{VAT}_{D E X A}$ in the current study. Further, there were no significant predictors of $\mathrm{VAT}_{U S}$ in men, stressing the importance of assessing VAT when evaluating metabolic health. Interestingly, HDL was a negative predictor of LM, metabolic rate, and $\mathrm{RER}_{\text {rest }}$ in the group overall. While further investigation into this relationship is required, these results may implicate HDL as a blood marker of non-traditional measures of metabolic health. High leptin and estradiol levels in men may be an indication of excess fat accumulation and an early sign of metabolic dysregulation. In women, high insulin is likely a strong predictor of greater VAT accumulation and its associated risks. Evaluation of hormonal profiles, in addition to blood lipid markers, may be valuable in the early identification and treatment of metabolic health.

Limitations exist in all studies. Exercise is known to be an important factor in metabolic health and weight regulation, typically improving health status. Although individuals were asked about their exercise habits, individuals were recruited for the current study based on health 
status, not exercise habits. However, regardless of exercise status, all individuals were still considered overweight or obese based on BMI and \%fat. Further, all individuals had maintained their weight within $4.5 \mathrm{~kg}$ for at least three months prior to testing, suggesting that despite potential benefits of exercise, other mechanisms were preventing these individuals from reaching a normal weight. Results and techniques used in the current study offer a more complete picture of the metabolic status of these individuals. Future exercise or dietary interventions that aim to decrease VAT, increase quality LM, improve fuel utilization, and restore hormonal balance may be effective.

In conclusion, traditional measures of metabolic dysfunction may not give a complete picture of metabolic health in overweight and obese adults. Other components of body composition have important associations with components of metabolic health, even in the presence of excess FM, and should be considered when determining metabolic health risk. Total body fat may have strong associations with hormonal factors, while VAT is more closely related to signs of insulin resistance, especially in women. Lean mass is generally associated with positive health benefits, but accounting for intramuscular fat may be an important factor when evaluating overweight and obese adults. Future studies characterizing intramuscular fat and corresponding influences on metabolic rate and fuel utilization in obese populations should be explored. Ultrasound may be a feasible option for clinical settings to evaluate VAT, improving the accuracy of evaluating abdominal obesity related risk and early detection of metabolic diseases. Metabolic syndrome is defined by excess abdominal fat, dyslipidemia, and insulin resistance, but these risk factors are the result of an accumulation of factors that could be prevented. Results of this study support the evaluation of hormonal profiles as a sign of 
developing dysfunction, while assessments of fat distribution, LM, metabolic rate, and fuel utilization could guide interventions for preventing the development of further dysfunction. 


\section{TABLES}

Table 1: Subject characteristics (Mean \pm standard deviation [SD])

\begin{tabular}{|c|c|c|c|}
\hline & Total & Male & Female \\
\hline $\mathbf{N}$ & 49 & 23 & 26 \\
\hline Age (yrs) & $35.0 \pm 8.9$ & $37.4 \pm 10.3$ & $32.8 \pm 6.9$ \\
\hline Height (cm) & $170.7 \pm 9.7^{*}$ & $178.1 \pm 6.4$ & $164.1 \pm 7.1$ \\
\hline Weight (kg) & $97.9 \pm 17.7$ & $102.2 \pm 15.1$ & $94.2 \pm 19.3$ \\
\hline BMI $\left(\mathbf{k g} \cdot \mathbf{m}^{-2}\right)$ & $33.6 \pm 5.2$ & $32.1 \pm 3.3$ & $34.9 \pm 6.2$ \\
\hline FM (kg) & $39.2 \pm 10.8^{*}$ & $34.8 \pm 8.8$ & $43.1 \pm 11.0$ \\
\hline LM (kg) & $58.7 \pm 12.1^{*}$ & $67.4 \pm 8.6$ & $51.0 \pm 9.4$ \\
\hline LMI $\left(\mathbf{k g} \cdot \mathbf{m}^{-2}\right)$ & $20.0 \pm 2.6^{*}$ & $21.2 \pm 1.7$ & $18.9 \pm 2.9$ \\
\hline$\%$ fat & $40.0 \pm 7.3^{*}$ & $33.8 \pm 4.8$ & $45.5 \pm 4.1$ \\
\hline VAT (cm) & $6.0 \pm 1.8$ & $6.5 \pm 1.9$ & $5.5 \pm 1.6$ \\
\hline RMR (kcal/day) & $1813.2 \pm 311.2^{*}$ & $2011.1 \pm 259.1$ & $1638.2 \pm 242.8$ \\
\hline RER rest & $0.9 \pm 0.1$ & $0.9 \pm 0.0$ & $0.8 \pm 0.1$ \\
\hline RERbike & $1.0 \pm 0.1$ & $1.0 \pm 0.1$ & $1.0 \pm 0.1$ \\
\hline TC (mg/dL) & $185.5 \pm 39.5$ & $191.4 \pm 35.0$ & $179.4 \pm 44.5$ \\
\hline LDL (mg/dL) & $118.8 \pm 34.3$ & $124.3 \pm 29.6$ & $113.0 \pm 38.4$ \\
\hline HDL (mg/dL) & $44.6 \pm 12.9^{*}$ & $39.0 \pm 7.9$ & $50.5 \pm 14.5$ \\
\hline TRG (mg/dL) & $110.7 \pm 73.5^{*}$ & $140.7 \pm 87.7$ & $79.3 \pm 35.2$ \\
\hline GLUC (mg/dL) & $87.2 \pm 22.2$ & $92.8 \pm 29.6$ & $81.4 \pm 7.0$ \\
\hline Insulin (uIU/mL) & $9.7 \pm 7.4$ & $8.5 \pm 4.9$ & $10.9 \pm 9.2$ \\
\hline HOMA-IR & $1.2 \pm 0.9$ & $1.1 \pm 0.6$ & $1.4 \pm 1.1$ \\
\hline Cortisol $(\mu \mathrm{g} / \mathrm{dL})$ & $0.3 \pm 0.2$ & $0.3 \pm 0.2$ & $0.3 \pm 0.2$ \\
\hline Estradiol (pg/mL) & $2.0 \pm 0.8$ & $1.7 \pm 0.8$ & $2.2 \pm 0.8$ \\
\hline Leptin (ng/mL) & $36.1 \pm 28.9^{*}$ & $15.0 \pm 10.9$ & $58.1 \pm 25.2$ \\
\hline
\end{tabular}

*significant difference between males and females $(\mathrm{p}<0.05)$ 
Table 2: Risk stratification and frequencies based on BMI, \%fat, and metabolic syndrome risk factors.

\begin{tabular}{|c|c|c|}
\hline & Stratification & $\mathbf{N}(\%)$ \\
\hline \multirow[t]{4}{*}{ BMI } & Overweight (25.0-29.9) & $13(26.5 \%)$ \\
\hline & Obese (30-34.9) & $14(28.6 \%)$ \\
\hline & Obese II (35-39.9) & $18(36.73 \%)$ \\
\hline & Obese III $(\geq 40)$ & $4(8.6 \%)$ \\
\hline \multirow[t]{2}{*}{ \% fat } & Moderate $(\mathrm{M}<25 \% ; \mathrm{F}<38 \%)$ & $1(2.0 \%)$ \\
\hline & High $(M \geq 25 \% ; F \geq 38 \%)$ & $48(98.0 \%)$ \\
\hline \multirow[t]{5}{*}{ Metabolic Syndrome } & 0 Risk Factors & $14(31.1 \%)$ \\
\hline & 1 Risk Factor & $18(40.0 \%)$ \\
\hline & 2 Risk Factors & $12(26.7 \%)$ \\
\hline & 3 Risk Factors & $1(2.2 \%)$ \\
\hline & 4 Risk Factors & $0(0 \%)$ \\
\hline \multirow[t]{7}{*}{ Additional Metabolic Risk Factors } & 0 Risk Factors & $2(4.4 \%)$ \\
\hline & 1 Risk Factor & $7(15.6 \%)$ \\
\hline & 2 Risk Factors & $14(31.1 \%)$ \\
\hline & 3 Risk Factors & $11(24.4 \%)$ \\
\hline & 4 Risk Factors & $4(8.9 \%)$ \\
\hline & 5 Risk Factors & $6(13.3 \%)$ \\
\hline & 6 Risk Factors & $1(2.2 \%)$ \\
\hline
\end{tabular}

Note: Metabolic syndrome defined as the presence of 3+ risk factors including: abdominal obesity (VAT; $>7 \mathrm{~cm}$ ), elevated triglycerides $(\geq 150 \mathrm{mg} / \mathrm{dl})$, low HDL cholesterol (men $<40$ $\mathrm{mg} / \mathrm{dl}$, women $<50 \mathrm{mg} / \mathrm{dl})$, and elevated fasting glucose $(\geq 110 \mathrm{mg} / \mathrm{dl})$. Additional

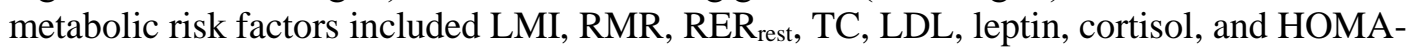
IR, in addition to the traditional metabolic syndrome risk factors. 
Table 3: Stratification and frequencies based on metabolic and hormonal factors.

\begin{tabular}{|c|c|c|}
\hline & Stratification & $\mathbf{N}(\%)$ \\
\hline VAT & $\begin{array}{r}\text { Low }(<7 \mathrm{~cm}) \\
\text { Moderate }(\mathrm{M} 7-9 \mathrm{~cm} ; \mathrm{W} 7-8 \mathrm{~cm}) \\
\text { High }(\mathrm{M}>9 \mathrm{~cm} ; \mathrm{W}>8 \mathrm{~cm})\end{array}$ & $\begin{array}{c}36(73.5 \%) \\
10(20.4 \%) \\
3(6.1 \%)\end{array}$ \\
\hline Glucose & $\begin{array}{r}\text { Low }(<70 \mathrm{mg} / \mathrm{dL}) \\
\text { Normal }(70-110 \mathrm{mg} / \mathrm{dL}) \\
\text { High }(\geq 110 \mathrm{mg} / \mathrm{dL})\end{array}$ & $\begin{aligned} 1 & (2.2 \%) \\
42 & (93.3 \%) \\
2 & (4.4 \%)\end{aligned}$ \\
\hline Triglycerides & $\begin{array}{l}\text { Normal }(<150 \mathrm{mg} / \mathrm{dL}) \\
\text { High }(\geq 150 \mathrm{mg} / \mathrm{dL})\end{array}$ & $\begin{array}{c}38(84.4 \%) \\
7(15.6 \%)\end{array}$ \\
\hline HDL & $\begin{array}{r}\text { Low }(\mathrm{M}<40 \mathrm{mg} / \mathrm{dL} ; \mathrm{W}<50 \mathrm{mg} / \mathrm{dL}) \\
\text { Normal }(\mathrm{M} \geq 40 \mathrm{mg} / \mathrm{dL} ; \mathrm{W} \geq 50 \mathrm{mg} / \mathrm{dL})\end{array}$ & $\begin{array}{l}25(55.6 \%) \\
20(44.4 \%)\end{array}$ \\
\hline LMI & $\begin{array}{r}\text { Low }(<10 \%) \\
\text { Normal }\left(10^{\text {th }}-90^{\text {th }} \%\right) \\
\text { High }>90 \% \\
>97 \%\end{array}$ & $\begin{array}{c}0(0 \%) \\
33(67.3 \%) \\
11(22.4 \%) \\
5(10.2 \%)\end{array}$ \\
\hline RMR & $\begin{array}{r}\text { Low }(<125.6 \mathrm{kcal} / \mathrm{d}) \\
\text { Normal }( \pm 125.6 \mathrm{kcal} / \mathrm{d}) \\
\text { High }(>125.6 \mathrm{kcal} / \mathrm{d})\end{array}$ & $\begin{array}{c}22(44.9 \%) \\
24(49.0 \%) \\
3(6.1 \%)\end{array}$ \\
\hline RER $_{\text {rest }}$ & $\begin{array}{r}\text { Low }(<0.82) \\
\text { Normal }(0.85 \pm 0.03) \\
\text { High }(>0.88)\end{array}$ & $\begin{array}{l}13(26.5 \%) \\
28(57.1 \%) \\
8(16.3 \%)\end{array}$ \\
\hline Total Cholesterol & $\begin{array}{r}\text { Low }(<100 \mathrm{mg} / \mathrm{dL}) \\
\text { Normal }(100-199 \mathrm{mg} / \mathrm{dL}) \\
\text { High }(>200 \mathrm{mg} / \mathrm{dL})\end{array}$ & $\begin{array}{c}4(8.2 \%) \\
30(61.2 \%) \\
15(30.6 \%)\end{array}$ \\
\hline LDL & $\begin{array}{r}\text { Normal }(<100 \mathrm{mg} / \mathrm{dL}) \\
\text { Above normal }(100-160 \mathrm{mg} / \mathrm{dL}) \\
\text { High }(>160 \mathrm{mg} / \mathrm{dL})\end{array}$ & $\begin{array}{l}13(28.9 \%) \\
26(57.8 \%) \\
6(13.3 \%)\end{array}$ \\
\hline HOMA-IR & $\begin{array}{r}\text { Normal }(\leq 2.5) \\
\text { High }(>2.5)\end{array}$ & $\begin{array}{c}44(97.8 \%) \\
1(2.2 \%)\end{array}$ \\
\hline Leptin & $\begin{array}{r}\text { Low }\left(<10^{\text {th }} \text { percentile }\right) \\
\text { Normal }\left(10^{\text {th }}-90^{\text {th }} \text { percentile }\right) \\
\text { High }\left(>90^{\text {th }} \text { percentile }\right)\end{array}$ & $\begin{array}{c}0(0.0 \%) \\
14(31.1 \%) \\
31(68.9 \%)\end{array}$ \\
\hline Estradiol & $\begin{array}{r}\text { Low }(<1.35 \mathrm{pg} / \mathrm{mL}) \\
\text { Normal }(1.35-2.97 \mathrm{pg} / \mathrm{mL}) \\
\text { High }(>2.97 \mathrm{pg} / \mathrm{mL})\end{array}$ & $\begin{array}{c}11(22.4 \%) \\
35(71.4 \%) \\
3(6.1 \%)\end{array}$ \\
\hline Cortisol & $\begin{array}{r}\text { Low } \\
\text { Normal } \\
\text { High }\end{array}$ & $\begin{array}{c}7(14.3 \%) \\
42(85.7 \%) \\
0(0 \%)\end{array}$ \\
\hline
\end{tabular}

Note: VAT, glucose, triglycerides, and HDL are considered risk factors for metabolic syndrome. 


\section{FIGURES}

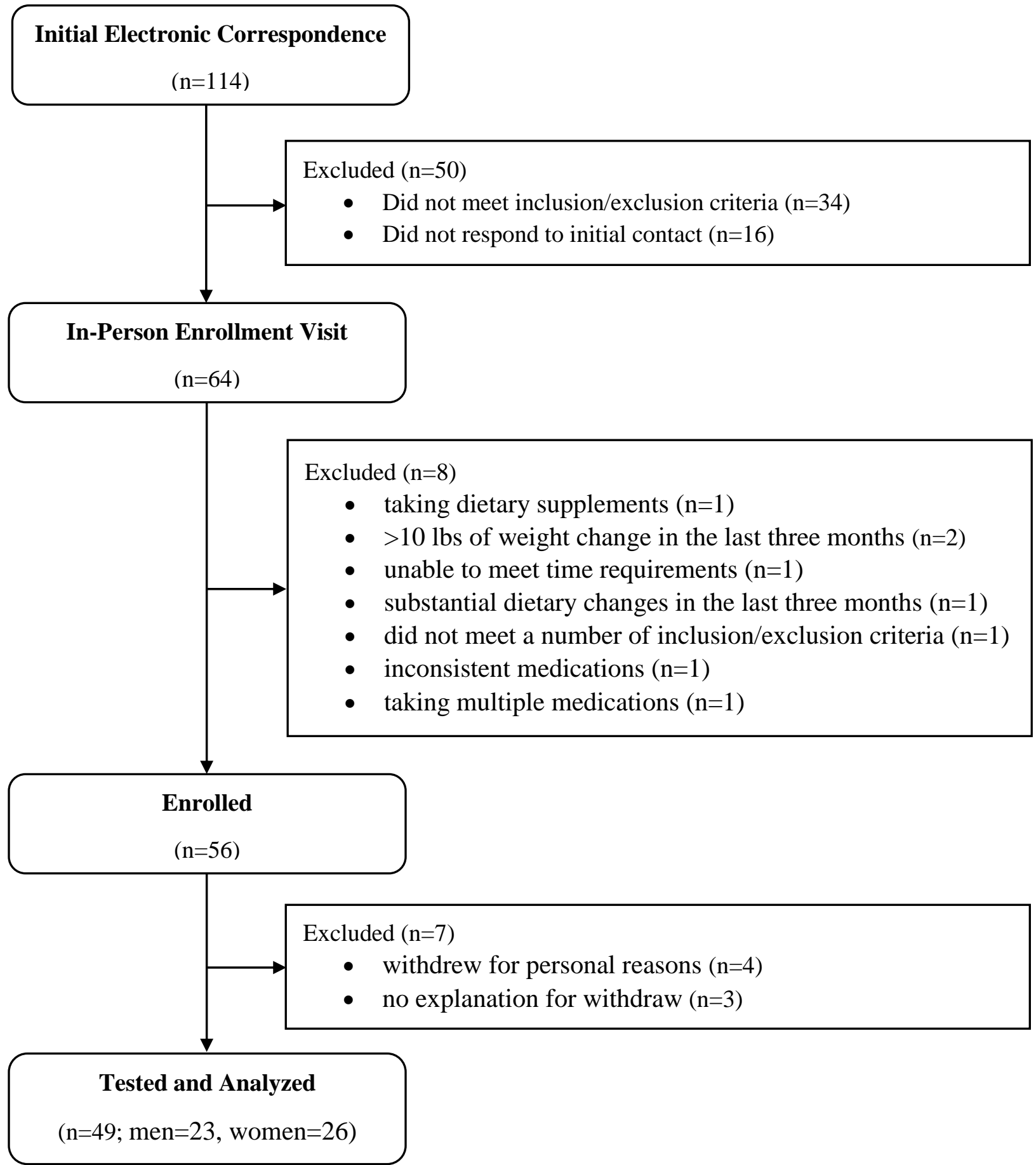

Figure 1: CONSORT flow diagram of subject recruitment and enrollment for study participation and analysis. 


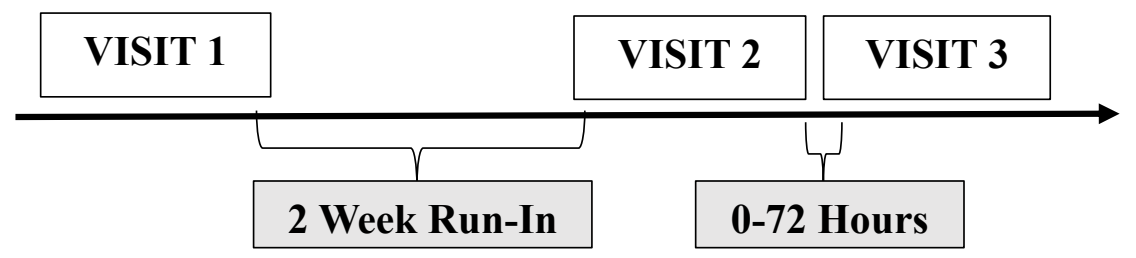

\section{Visit 1: Enrollment}

- Informed consent

- Health history questionnaire

- Age, height, weight, BMI

- 4-day dietary intake analysis and interpretation
Visit 2: Testing

- Resting metabolic rate

- Body composition

- Fasted blood draw

- Saliva Sample

Figure 2: Experimental timeline. 

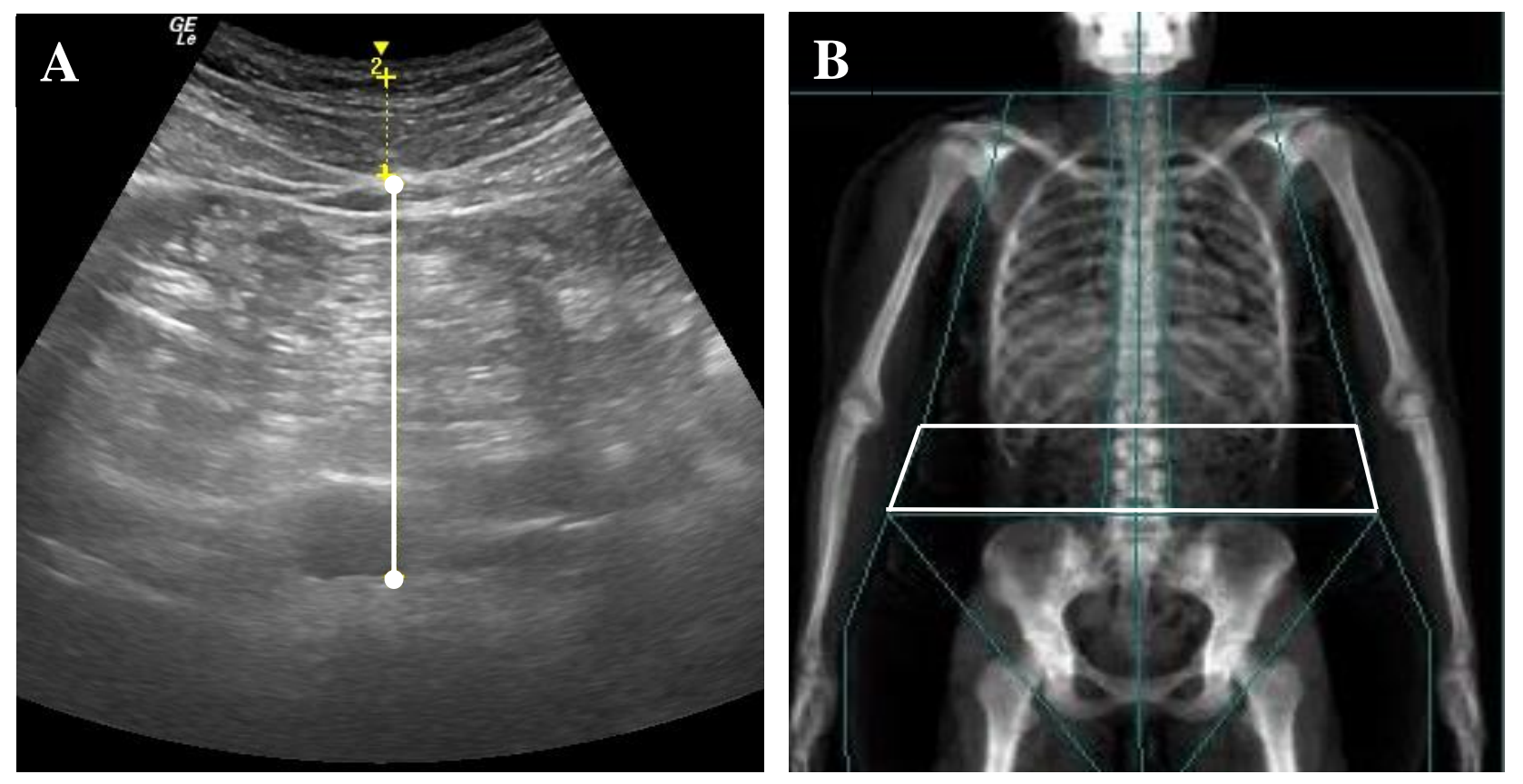

Figure 3: Measurements of VAT. (A) Abdominal US scan; $\mathrm{VAT}_{U S}$ thickness was measured between the interior border of the rectus abdominis and the posterior wall of the aorta. (B) Android region-of-interest set by DEXA software to quantify VAT $\mathrm{V}_{D E X A}$. Parameters of the region span from the top of the iliac crest to a height $20 \%$ of the distance from the top of the iliac crest to the base of the skull to the width of the torso. 


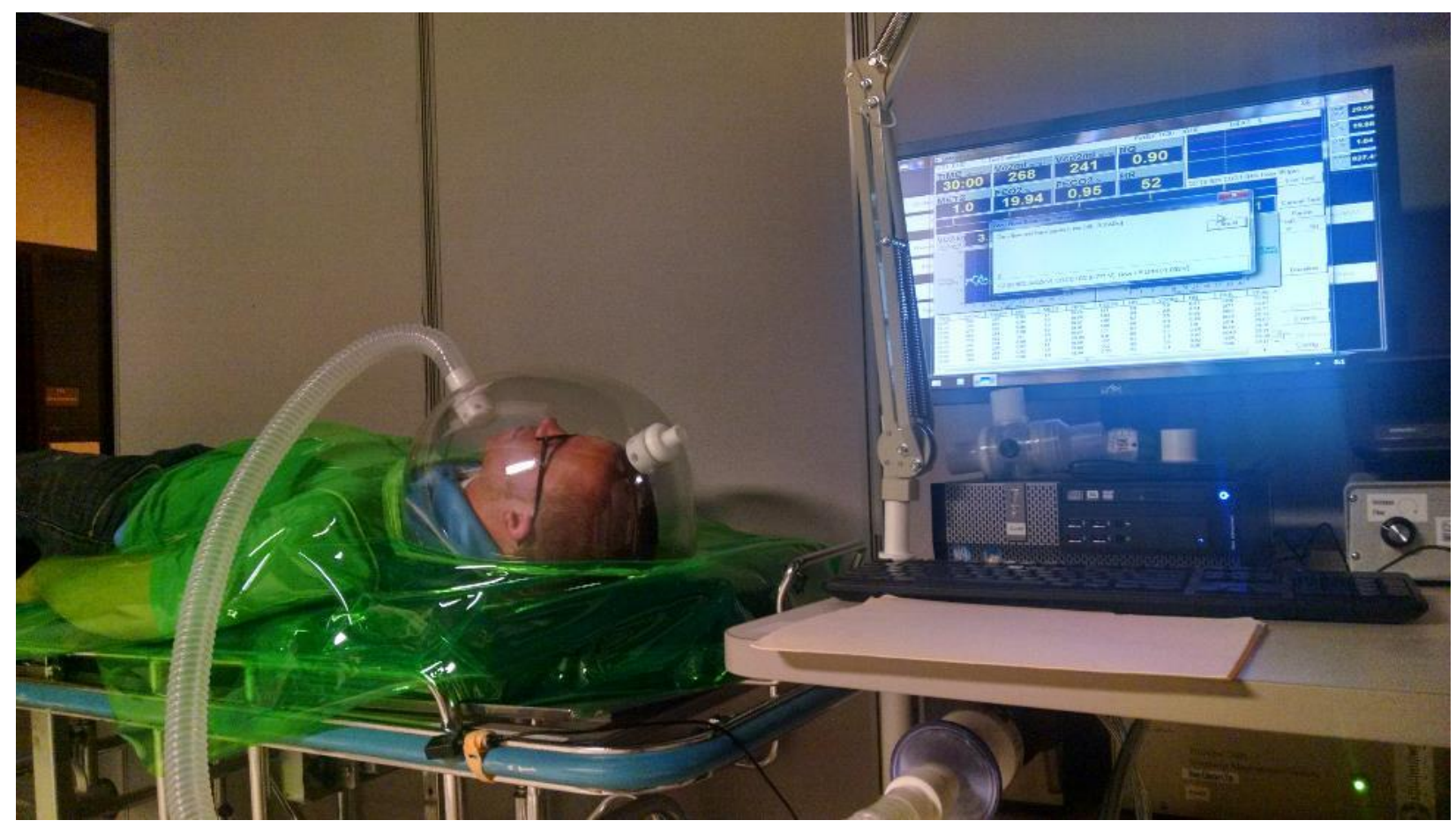

Figure 4: Resting metabolic rate ventilated canopy with indirect calorimetry. 


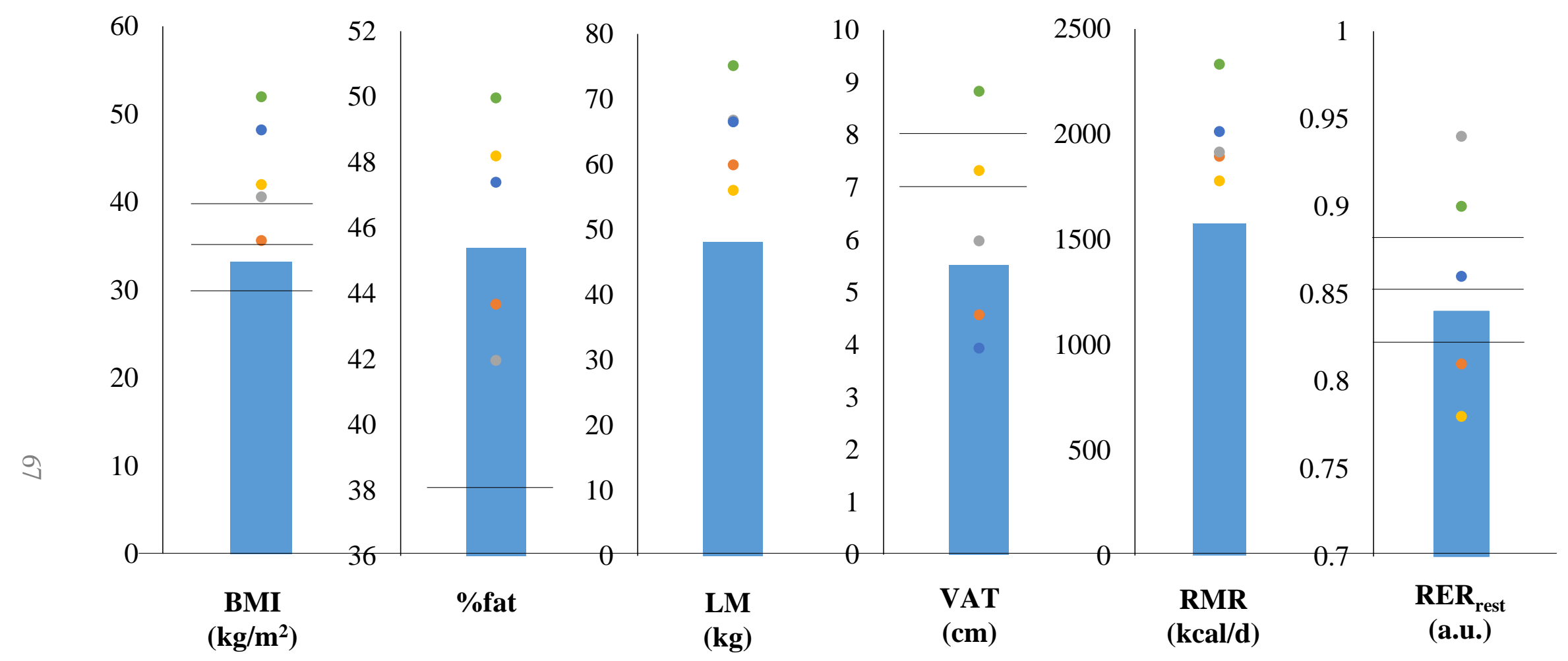

Figure 5: Five females with LMI $>97^{\text {th }}$ percentile based on age and race, (represented by the colored dots) compared with the female group average (represented by the blue bars). Of the five women considered to have above average LM, all were considered to be in the obese II or obese III categories and had a \%fat $>40 \%$; two were considered to have moderate $(7-8 \mathrm{~cm})$ and high VAT (>8cm). All five women had normal metabolic rates $( \pm 125.6 \mathrm{kcal} / \mathrm{d}$ from predicted); two had an RER $>0.88$, potentially indicating increased reliance on carbohydrate at rest; two had an RER $<0.82$, potentially indicating greater reliance on fat at rest; one had an RER=0.86, potentially indicating equal contribution of carbohydrate and fat at rest. All women had normal TC, TRG, and GLUC while four of the five had normal LDL. 

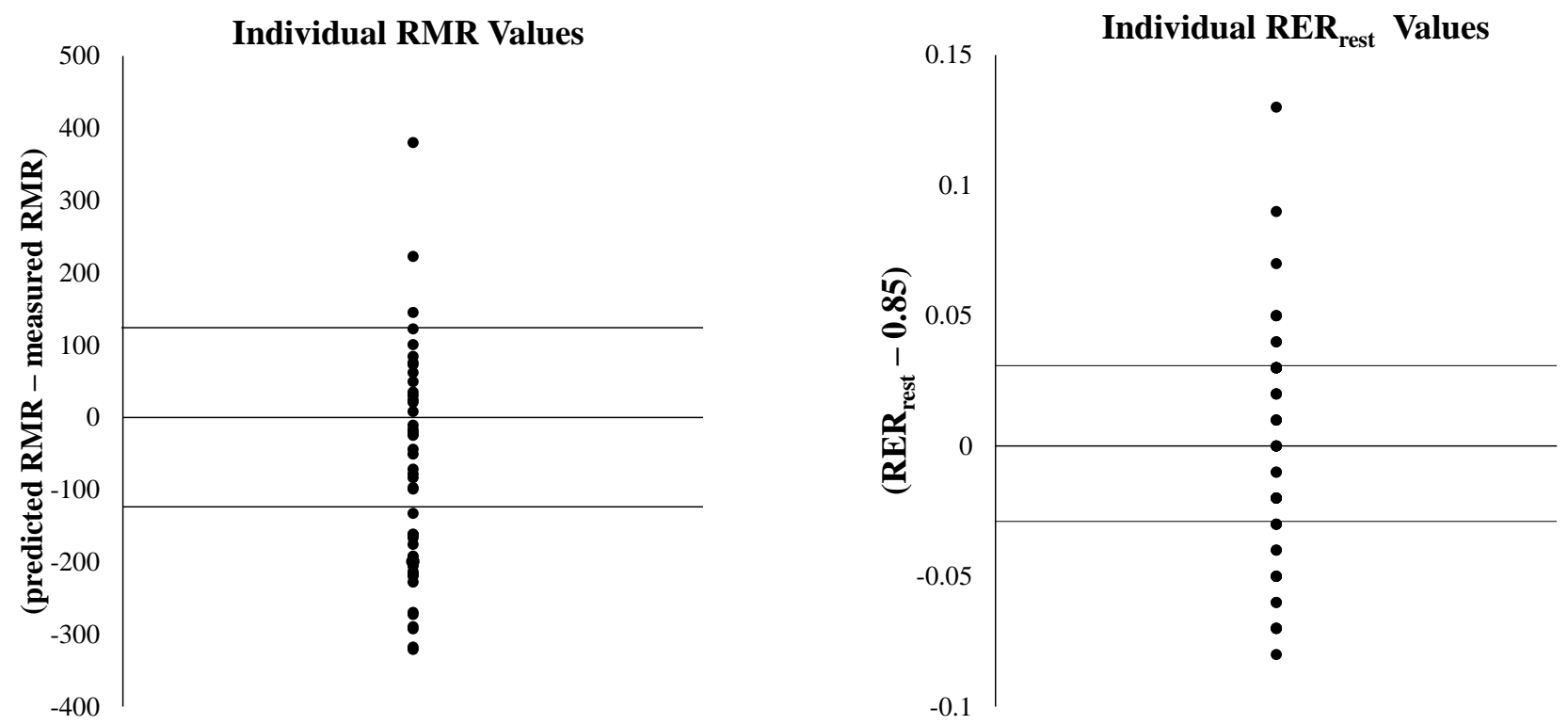

Figure 6: Individual RMR and $\mathrm{RER}_{\text {rest }}$ values. Resting metabolic rate is represented as the differences between predicted and measured. Respiratory exchange ratio values are represented as the difference between measured and 0.85 a.u. High and low cutoffs were set at SEM for RMR and $\mathrm{RER}_{\text {rest }}$ respectively. 


\section{REFERENCES}

1. Grundy, S.M., et al., Definition of metabolic syndrome: Report of the National Heart, Lung, and Blood Institute/American Heart Association conference on scientific issues related to definition. Circulation, 2004. 109(3): p. 433-8.

2. Isomaa, B., et al., Cardiovascular morbidity and mortality associated with the metabolic syndrome. Diabetes Care, 2001. 24(4): p. 683-9.

3. Ogden, C.L., et al., Prevalence of Childhood and Adult Obesity in the United States, 2011-2012. JAMA, 2014. 311(8): p. 806.

4. Wildman, R.P., Muntner, P., Reynolds, K., McGinn, A. P., Rajpathak, S., Wylie-Rosett, J., \& Sowers, M. R., The obese without cardiometabolic risk factor clustering and the normal weight with cardiometabolic risk factor clustering. Archives of internal medicine, 2008. 168(15): p. 1617-1624.

5. $\quad$ Primeau, V., et al., Characterizing the profile of obese patients who are metabolically healthy. International Journal of Obesity, 2010. 35(7): p. 971-981.

6. Weiss, E.C., et al., Weight regain in US adults who experienced substantial weight loss, 1999-2002. American journal of preventive medicine, 2007. 33(1): p. 34-40.

7. Wadden, T., et al., Treatment of obesity by very low calorie diet, behavior therapy, and their combination: a five-year perspective. International Journal of Obesity, 1988. 13: $\mathrm{p}$. 39-46.

8. Bradshaw, P.T., K.L. Monda, and J. Stevens, Metabolic Syndrome in Healthy Obese, Overweight, and Normal Weight Individuals: The Atherosclerosis Risk in Communities Study. Obesity, 2012.

9. Müller, M.J., et al., Beyond the body mass index: tracking body composition in the pathogenesis of obesity and the metabolic syndrome. Obesity Reviews, 2012. 13: p. 6-13.

10. Karelis, A.D., et al., Metabolic and Body Composition Factors in Subgroups of Obesity: What Do We Know? The Journal of Clinical Endocrinology \& Metabolism, 2004. 89(6): p. 2569-2575. 
11. Brochu, M., et al., What are the physical characteristics associated with a normal metabolic profile despite a high level of obesity in postmenopausal women? J Clin Endocrinol Metab, 2001. 86(3): p. 1020-5.

12. Cnop, M., Landchild, M. J., Vidal, J., Havel, P. J., Knowles, N. G., Carr, D. R., ... \& Kahn, S. E., The concurrent accumulation of intra-abdominal and subcutaneous fat explains the association between insulin resistance and plasma leptin concentrations. Diabetes, 2002. 51(4): p. 1005-1015.

13. St-Onge, M.P., I. Janssen, and S.B. Heymsfield, Metabolic syndrome in normal-weight Americans: new definition of the metabolically obese, normal-weight individual. Diabetes Care, 2004. 27(9): p. 2222-8.

14. Kershaw, E.E. and J.S. Flier, Adipose tissue as an endocrine organ. The Journal of Clinical Endocrinology \& Metabolism, 2004. 89(6): p. 2548-2556.

15. Shi, H. and D. Clegg, Sex differences in the regulation of body weight. Physiology \& behavior, 2009. 97(2): p. 199-204.

16. Park, K.-G., et al., Relationship between serum adiponectin and leptin concentrations and body fat distribution. Diabetes Research and Clinical Practice, 2004. 63(2): p. 135142.

17. Minocci, A., et al., Leptin plasma concentrations are dependent on body fat distribution in obese patients. Int J Obes Relat Metab Disord, 2000. 24(9): p. 1139-44.

18. Meier, U. and A.M. Gressner, Endocrine regulation of energy metabolism: review of pathobiochemical and clinical chemical aspects of leptin, ghrelin, adiponectin, and resistin. Clinical Chemistry, 2004. 50(9): p. 1511-1525.

19. Niswender, K.D., D.G. Baskin, and M.W. Schwartz, Insulin and its evolving partnership with leptin in the hypothalamic control of energy homeostasis. Trends in Endocrinology \& Metabolism, 2004. 15(8): p. 362-369.

20. Hukshorn, C.J., \& Saris, W. H., Leptin and energy expenditure. Current Opinion in Clinical Nutrition \& Metabolic Care, 2004. 7(6): p. 629-633.

21. Kennedy, A., Gettys, T. W., Watson, P., Wallace, P., Ganaway, E., Pan, Q., \& Garvey, W. T., The metabolic significance of leptin in humans: gender-based differences in 
relationship to adiposity, insulin sensitivity, and energy expenditure. Journal of Clinical Endocrinology \& Metabolism., 1997. 82(4): p. 1293-1300.

22. Blouin, K., A. Boivin, and A. Tchernof, Androgens and body fat distribution. J Steroid Biochem Mol Biol, 2008. 108(3-5): p. 272-80.

23. Zumoff, B., Hormonal abnormalities in obesity. Acta Medica Scandinavica, 1987. 222(S723): p. 153-160.

24. Schneider, G., et al., Increased estrogen production in obese men. J Clin Endocrinol Metab, 1979. 48(4): p. 633-8.

25. Björntorp, P., Endocrine abnormalities of obesity. Metabolism, 1995. 44: p. 21-23.

26. Bjorntorp, P., Do stress reactions cause abdominal obesity and comorbidities? Obes Rev, 2001. 2(2): p. 73-86.

27. Mårin, P., et al., Cortisol secretion in relation to body fat distribution in obese premenopausal women. Metabolism, 1992. 41(8): p. 882-886.

28. Kelley, D.E., et al., Skeletal muscle fatty acid metabolism in association with insulin resistance, obesity, and weight loss. American Journal of Physiology-Endocrinology And Metabolism, 1999. 277(6): p. E1130-E1141.

29. Johnstone, A.M., et al., Factors influencing variation in basal metabolic rate include fatfree mass, fat mass, age, and circulating thyroxine but not sex, circulating leptin, or triiodothyronine. Am J Clin Nutr, 2005. 82(5): p. 941-8.

30. Wolfe, R.R., The underappreciated role of muscle in health and disease. The American journal of clinical nutrition, 2006. 84(3): p. 475-482.

31. Zurlo, F., et al., Low ratio of fat to carbohydrate oxidation as predictor of weight gain: study of 24-h RQ. American Journal of Physiology-Endocrinology And Metabolism, 1990. 259(5): p. E650-E657.

32. Heyward, V., ASEP methods recommendation: body composition assessment. J Exerc Physiol, 2001. 4(4): p. 1-12. 
33. Lefebvre, A.M., et al., Depot-specific differences in adipose tissue gene expression in lean and obese subjects. Diabetes, 1998. 47(1): p. 98-103.

34. Ribeiro-Filho, F.F., et al., Two-hour insulin determination improves the ability of abdominal fat measurement to identify risk for the metabolic syndrome. Diabetes Care, 2003. 26(6): p. 1725-30.

35. Leite, C.C., et al., Intra-abdominal thickness by ultrasonography to predict risk factors for cardiovascular disease and its correlation with anthropometric measurements. Metabolism, 2002. 51(8): p. 1034-1040.

36. Stoner, L., et al., Reliability tests and guidelines for B-mode ultrasound assessment of central adiposity. European Journal of Clinical Investigation, 2015. 45(11): p. 12001208.

37. Brooks, G.A., T.D. Fahey, and K.M. Baldwin, Exercise physiology: human bioenergetics and its applications. 4th ed. 2005, Boston: McGraw-Hill. xxi, 876, 7, 22 p.

38. Dvorak, R.V., DeNino, W. F., Ades, P. A., \& Poehlman, E. T., Phenotypic characteristics associated with insulin resistance in metabolically obese but normal weight young women. Diabetes, 1999. 48(1): p. 2210-2214.

39. Reaven, G., Hypertension and associated metabolic abnormalities-the role of insulin resistance and the sympathoadrenal system. N. Engl. J. Med., 1996. 334: p. 374-381.

40. Goodpaster, B.H., et al., Subcutaneous abdominal fat and thigh muscle composition predict insulin sensitivity independently of visceral fat. Diabetes, 1997. 46(10): p. 15791585.

41. Yoshizumi, T., et al., Abdominal Fat: Standardized Technique for Measurement at CT 1. Radiology, 1999. 211(1): p. 283-286.

42. Armellini, F., et al., Total and intra-abdominal fat measurements by ultrasound and computerized tomography. Int J Obes Relat Metab Disord, 1993. 17(4): p. 209-14.

43. Stolk, R., et al., Validity and reproducibility of ultrasonography for the measurement of intra-abdominal adipose tissue. International journal of obesity and related metabolic disorders: journal of the International Association for the Study of Obesity, 2001. 25(9): p. 1346-1351. 
44. Klok, M.D., S. Jakobsdottir, and M.L. Drent, The role of leptin and ghrelin in the regulation of food intake and body weight in humans: a review. Obesity Reviews, 2007. 8(1): p. 21-34.

45. Maffeis, C., et al., Insulin sensitivity is correlated with subcutaneous but not visceral body fat in overweight and obese prepubertal children. J Clin Endocrinol Metab, 2008. 93(6): p. 2122-8.

46. Gower, B.A., et al., Leptin in postmenopausal women: influence of hormone therapy, insulin, and fat distribution. J Clin Endocrinol Metab, 2000. 85(5): p. 1770-5.

47. Maffei, M., et al., Leptin levels in human and rodent: measurement of plasma leptin and ob RNA in obese and weight-reduced subjects. Nature medicine, 1995(1): p. 1155-61.

48. Blouin, K., A. Boivin, and A. Tchernof, Androgens and body fat distribution. The Journal of steroid biochemistry and molecular biology, 2008. 108(3): p. 272-280.

49. Drapeau, V., et al., Is visceral obesity a physiological adaptation to stress? Panminerva medica, 2003. 45(3): p. 189-196.

50. Randle, P., et al., The glucose fatty-acid cycle its role in insulin sensitivity and the metabolic disturbances of diabetes mellitus. The Lancet, 1963. 281(7285): p. 785-789.

51. Roubenoff, R., Sarcopenic obesity: the confluence of two epidemics. Obesity research, 2004. 12(6): p. 887-888.

52. Goodpaster, B.H., et al., The loss of skeletal muscle strength, mass, and quality in older adults: the health, aging and body composition study. The Journals of Gerontology Series A: Biological Sciences and Medical Sciences, 2006. 61(10): p. 1059-1064.

53. Ravussin, E. and J.F. Gautier, Metabolic predictors of weight gain. Int J Obes Relat Metab Disord, 1999. 23 Suppl 1: p. 37-41.

54. Levine, J.A., Non-exercise activity thermogenesis. Proceedings of the Nutrition Society, 2003. 62(03): p. 667-679. 
55. Stiegler, P. and A. Cunliffe, The role of diet and exercise for the maintenance of fat-free mass and resting metabolic rate during weight loss. Sports Medicine, 2006. 36(3): p. 239-262.

56. Boden, G., et al., Effect of fasting on serum leptin in normal human subjects. The Journal of Clinical Endocrinology \& Metabolism, 1996. 81(9): p. 3419-3423.

57. Scarpace, P.J., et al., Leptin resistance exacerbates diet-induced obesity and is associated with diminished maximal leptin signalling capacity in rats. Diabetologia, 2005. 48(6): p. 1075-83.

58. Solomon, S.J., M.S. Kurzer, and D.H. Calloway, Menstrual cycle and basal metabolic rate in women. The American journal of clinical nutrition, 1982. 36(4): p. 611-616.

59. Matarese, L.E., Indirect calorimetry: technical aspects. Journal of the American Dietetic Association, 1997. 97(10): p. S154-S160.

60. Goedecke, J.H., et al., Determinants of the variability in respiratory exchange ratio at rest and during exercise in trained athletes. American Journal of PhysiologyEndocrinology And Metabolism, 2000. 279(6): p. E1325-E1334.

61. Flatt, J., et al., Effects of dietary fat on postprandial substrate oxidation and on carbohydrate and fat balances. Journal of Clinical Investigation, 1985. 76(3): p. 1019.

62. Larson, D., et al., Energy metabolism in weight-stable postobese individuals. The American journal of clinical nutrition, 1995. 62(4): p. 735-739.

63. Marra, M., et al., Fasting respiratory quotient as a predictor of weight changes in nonobese women. International journal of obesity and related metabolic disorders: journal of the International Association for the Study of Obesity, 1998. 22(6): p. 601-603.

64. Horton, T.J., et al., Fuel metabolism in men and women during and after long-duration exercise. Journal of Applied Physiology, 1998. 85(5): p. 1823-1832.

65. Tarnopolsky, L., et al., Gender differences in substrate for endurance exercise. Journal of Applied Physiology, 1990. 68(1): p. 302-308. 
66. Colberg, S.R., et al., Skeletal muscle utilization of free fatty acids in women with visceral obesity. Journal of Clinical Investigation, 1995. 95(4): p. 1846.

67. Ravussin, E., et al., Reduced rate of energy expenditure as a risk factor for body-weight gain. New England Journal of Medicine, 1988. 318(8): p. 467-472.

68. Wang, Z., et al., Multicomponent methods: evaluation of new and traditional soft tissue mineral models by in vivo neutron activation analysis. Am J Clin Nutr, 2002. 76(5): $\mathrm{p}$. 968-74.

69. Kaul, S., et al., Dual-energy X-ray absorptiometry for quantification of visceral fat. Obesity, 2012. 20(6): p. 1313-1318.

70. Gower, B.A. and A.M. Goss, A Lower-Carbohydrate, Higher-Fat Diet Reduces Abdominal and Intermuscular Fat and Increases Insulin Sensitivity in Adults at Risk of Type 2 Diabetes. Journal of Nutrition, 2014. 145(1): p. 177S-183S.

71. American College of Sports Medicine., et al., ACSM's guidelines for exercise testing and prescription. 8th ed. 2010, Philadelphia: Lippincott Williams \& Wilkins. xxi, 380 p.

72. Antonio, J., et al., Essentials of sports nutrition and supplements. 2009: Springer Science $\&$ Business Media.

73. Grundy, S.M., et al., Definition of metabolic syndrome: report of the National Heart, Lung, and Blood Institute/American Heart Association conference on scientific issues related to definition. Arterioscler Thromb Vasc Biol, 2004. 24(2): p. e13-8.

74. Fan, B., et al., National Health and Nutrition Examination Survey whole-body dualenergy X-ray absorptiometry reference data for GE lunar systems. Journal of Clinical Densitometry, 2014. 17(3): p. 344-377.

75. Jésus, P., et al., Validity of predictive equations for resting energy expenditure according to the body mass index in a population of 1726 patients followed in a Nutrition Unit. Clinical Nutrition, 2015. 34(3): p. 529-535.

76. Panel, N.C.E.P.N.E., Third Report of the National Cholesterol Education Program (NCEP) Expert Panel on Detection, Evaluation, and Treatment of High Blood Cholesterol in Adults (Adult Treatment Panel III) final report. Circulation, 2002. 106(25): p. 3143. 
77. Aardal, E. and A.C. Holm, Cortisol in saliva--reference ranges and relation to cortisol in serum. Eur J Clin Chem Clin Biochem, 1995. 33(12): p. 927-32.

78. Ruhl, C.E. and J.E. Everhart, Leptin concentrations in the United States: relations with demographic and anthropometric measures. Am J Clin Nutr, 2001. 74(3): p. 295-301.

79. Wallace, T.M., J.C. Levy, and D.R. Matthews, Use and abuse of HOMA modeling. Diabetes Care, 2004. 27(6): p. 1487-95.

80. Levy, J.C., D.R. Matthews, and M.P. Hermans, Correct homeostasis model assessment (HOMA) evaluation uses the computer program. Diabetes Care, 1998. 21(12): p. 2191-2.

81. Matthews, D., et al., Homeostasis model assessment: insulin resistance and $\beta$-cell function from fasting plasma glucose and insulin concentrations in man. Diabetologia, 1985. 28(7): p. 412-419.

82. Salgado, A.L.F.d.A., et al., Insulin resistance index (HOMA-IR) in the differentiation of patients with non-alcoholic fatty liver disease and healthy individuals. Arquivos de gastroenterologia, 2010. 47(2): p. 165-169.

83. Neeland, I.J., et al., Associations of visceral and abdominal subcutaneous adipose tissue with markers of cardiac and metabolic risk in obese adults. Obesity (Silver Spring), 2013. 21(9): p. E439-47.

84. Brochu, What are the physical characteristics associated with a normal metabolic profile despite a high level of obesity in postmenopausal women. 2001.

85. Anderson, R.M., et al., Impact of Visceral Fat on Skeletal Muscle Mass and Vice Versa in a Prospective Cohort Study: The Korean Sarcopenic Obesity Study (KSOS). PLoS One, 2014. 9(12): p. e115407.

86. Busetto, L., et al., Assessment of abdominal fat distribution in obese patients: anthropometry versus computerized tomography. International Journal of Obesity, 1992. 16: p. 731-731.

87. Ravussin, E. and J. Gautier, Metabolic predictors of weight gain. International Journal of Obesity \& Related Metabolic Disorders, 1999. 23. 
88. Poirier, P. and R.H. Eckel, Obesity and cardiovascular disease. Current atherosclerosis reports, 2002. 4(6): p. 448-453.

89. Shah, R.V., et al., Visceral Adiposity and the Risk of Metabolic Syndrome Across Body Mass Index. JACC: Cardiovascular Imaging, 2014. 7(12): p. 1221-1235.

90. Despres, J.-P., Cardiovascular Disease Under the Influence of Excess Visceral Fat. Critical Pathways in Cardiology: A Journal of Evidence-Based Medicine, 2007. 6(2): p. 51-59.

91. $\mathrm{Bi}, \mathrm{X}$., et al., DXA-measured visceral adipose tissue predicts impaired glucose tolerance and metabolic syndrome in obese Caucasian and African-American women. European Journal of Clinical Nutrition, 2015. 69(3): p. 329-336.

92. Björntorp, P., Metabolic implications of body fat distribution. Diabetes Care, 1991. 14(12): p. 1132-1143.

93. Naboush, A. and O. Hamdy, Measuring visceral and hepatic fat in clinical practice and clinical research. Endocrine Practice, 2013. 19(4): p. 587-589.

94. Lebon, J., et al., Is a small muscle mass index really detrimental for insulin sensitivity in postmenopausal women of various body composition status. J Musculoskelet Neuronal Interact, 2012. 12(3): p. 116-126.

95. Brochu, M., et al., Contribution of the lean body mass to insulin resistance in postmenopausal women with visceral obesity: a Monet study. Obesity, 2008. 16(5): p. 1085-1093.

96. Barsalani, R., M. Brochu, and I.J. Dionne, Is there a skeletal muscle mass threshold associated with the deterioration of insulin sensitivity in sedentary lean to obese postmenopausal women? Diabetes Research and Clinical Practice, 2013. 102(2): p. 123128.

97. Karelis, A.D., et al., Association of insulin sensitivity and muscle strength in overweight and obese sedentary postmenopausal women. Applied Physiology, Nutrition, and Metabolism, 2007. 32(2): p. 297-301.

98. Goodpaster, B.H., et al., Intramuscular lipid content is increased in obesity and decreased by weight loss. Metabolism, 2000. 49(4): p. 467-472. 
99. Goodpaster, B.H., et al., Attenuation of skeletal muscle and strength in the elderly: The Health ABC Study. Journal of Applied Physiology, 2001. 90(6): p. 2157-2165.

100. Johnstone, Factor influending variation in basal metabolic rate include fat-free mass, fat mass, age, and circulating thyroxine but not sex, circulating leptin or triiodothyronine. 2005.

101. Leibel, R.L., M. Rosenbaum, and J. Hirsch, Changes in energy expenditure resulting from altered body weight. New England Journal of Medicine, 1995. 332(10): p. 621-628.

102. Shook, R.P., et al., High respiratory quotient is associated with increases in body weight and fat mass in young adults. European Journal of Clinical Nutrition, 2015.

103. McMurray, R.G., et al., Examining variations of resting metabolic rate of adults: a public health perspective. Medicine and science in sports and exercise, 2014. 46(7): p. 1352.

104. Weyer, C., et al., Determinants of energy expenditure and fuel utilization in man: effects of body composition, age, sex, ethnicity and glucose tolerance in 916 subjects. International Journal of Obesity \& Related Metabolic Disorders, 1999. 23(7).

105. Isacco, L., P. Duché, and N. Boisseau, Influence of hormonal status on substrate utilization at rest and during exercise in the female population. Sports Medicine, 2012. 42(4): p. 327-342.

106. Saris, W.H., Sugars, energy metabolism, and body weight control. The American journal of clinical nutrition, 2003. 78(4): p. 850S-857S.

107. Shi, H., R.J. Seeley, and D.J. Clegg, Sexual differences in the control of energy homeostasis. Front Neuroendocrinol, 2009. 30(3): p. 396-404.

108. Zerradi, M., et al., Androgens, body fat Distribution and Adipogenesis. Curr Obes Rep, 2014. 3(4): p. 396-403. 